\title{
Influences of removing linear and nonlinear trends from climatic variables on temporal variations of annual reference crop evapotranspiration in Xinjiang,
}

\section{China}

\author{
$\mathrm{Yi} \mathrm{Li}^{*}{ }^{1}$, Ning Yao ${ }^{1}$, Henry Wai Chau ${ }^{2}$
}

1. College of Water Resources and Architecture Engineering, Northwest Agriculture and Forestry University, Yangling, Shaanxi, 712100, China;

2. Department of Soil and Physical Sciences, Faculty of Agriculture and Life Science, Lincoln University, Lincoln, Canterbury, 7647, New Zealand.

Corresponding author: Yi Li, Email: liyikitty@ 126.com

\begin{abstract}
Reference crop evapotranspiration $\left(E T_{\mathrm{o}}\right)$ is a key parameter in field irrigation scheduling, drought assessment and climate change research. $E T_{\mathrm{o}}$ uses key prescribed (or fixed or reference) land surface parameters for crops. The linear and nonlinear trends in different climatic variables (CVs) affect $E T_{\mathrm{o}}$ change. This research aims to reveal how $E T_{\mathrm{o}}$ responds after the related $\mathrm{CV}$ s were linearly and nonlinearly detrended over 1961-2013 in Xinjiang, China. The $E T_{0}$-related CVs included minimum $\left(T_{\min }\right)$, average $\left(T_{\text {ave }}\right)$, and maximum air temperatures $\left(T_{\max }\right)$, wind speed at $2 \mathrm{~m}$ $\left(U_{2}\right)$, relative humidity $(R H)$ and sunshine hour $(n) . E T_{\mathrm{o}}$ was calculated using the Penman-Monteith equation. A total of $29 E T_{\mathrm{o}}$ scenarios, including the original scenario, 14 scenarios in Group I ( $E T_{\mathrm{o}}$ was recalculated after removing linear trends from single or more CVs) and 14 scenarios in Group II ( $E T_{\mathrm{o}}$ was recalculated after removing nonlinear trends from the $\mathrm{CVs}$ ), were generated. The influence of $U_{2}$ was stronger than influences of the other CVs on $E T_{0}$ for both Groups I and II either in northern, southern or the entirety of Xinjiang. The weak influences of increased $T_{\min }, T_{\text {ave }}$ and $T_{\max }$ on increasing $E T_{\mathrm{o}}$ were masked by the strong effects of decreased $U_{2} \& n$ and increased $R H$ on
\end{abstract}


decreasing $E T_{\mathrm{o}}$. The effects of the trends in $\mathrm{CVs}$, especially $U_{2}$, on changing $E T_{\mathrm{o}}$ were clearly shown. Without the general decreases of $U_{2}, E T_{\mathrm{o}}$ would have increased in the past 53 years. Due to the non-monotone variations of the $\mathrm{CVs}$ and $E T_{\mathrm{o}}$, the results of nonlinearly detrending CVs on changing $E T_{\mathrm{o}}$ in Group II should be more plausible than the results of linearly detrending CVs in Group I. The decreasing $E T_{\mathrm{o}}$ led to a general relief in drought, which was indicated by the recalculated aridity index. Therefore, there would be a slightly lower risk of water utilization in Xinjiang, China.

Key words: reference crop evapotranspiration, temporal variation, climatic scenario, detrended climatic variable, Xinjiang

\section{Abbreviations}

$\mathrm{CV}$-climatic variable; $E T_{\mathrm{o}}$-reference crop evapotranspiration; $T$-air temperature; $T_{\min }$-minimum $T$; $T_{\text {ave-mean }} T ; T_{\max }$-maximum $T ; U$-wind speed; $U_{2}-U$ at $2 \mathrm{~m} ; R H$-relative humidity; $n$-sunshine hour; $P$-precipitation; NX-northern Xinjiang; SX-southern Xinjiang; EX-entire Xinjiang; EEMD-Ensemble empirical mode decomposition; MK-Mann-Kendall; MMK-modified MK; Z-MK statistic; $Z_{\mathrm{m}}-\mathrm{MMK}$ statistic; SQMK-Sequential Mann-Kendall; S-scenario; $b$-Sen’ s slope; $L S$-linear slope; $Y_{\mathrm{AC}}$-year with an abrupt change; $P_{\mathrm{sl}^{-}}$-significant level; $G$-soil heat flux; $e_{\mathrm{a}^{-}}$actual vapor pressure; $e_{\mathrm{s}}$-saturation vapor pressure; $\Delta$-slope of vapor pressure curve; $\gamma$-psychrometric constant; $R_{\mathrm{n}}$-net radiation; SD-standard error, RMSE-root mean square error.

\section{Introduction}

The global average land surface temperature increased by $0.85^{\circ} \mathrm{C}$ in the period from 1880 to 2012 (IPCC 2013). Faced with the challenges of global warming, it is crucial to know how the water availability and the agricultural water demands change, as a function of reference crop evapotranspiration $\left(E T_{\mathrm{o}}\right)$ variation (Espadafor et al. 2011). $E T_{\mathrm{o}}$ is widely used for water scheduling 
of irrigation areas and uses key prescribed (or fixed or reference) land surface parameters for crops. Accurate estimation of $E T_{\mathrm{o}}$ is needed for field irrigation scheduling (Allen et al. 1998), drought assessment (Budyko 1974) and climate change research (Tabari and Hosseinzadeh Talaee 2014). The available models for estimating $E T_{\mathrm{o}}$ include temperature-based approaches (Blaney and Criddle 1952; Hargreaves and Samani 1985; Thornthwaite 1948), radiation-based approaches (Slatyer and McIlroy 1961) and combination approaches (Allen et al. 1998; Priestley and Taylor 1972). Following an extensive analysis of different $E T_{\mathrm{o}}$ methods in many world-wide locations, the Penman-Monteith (PM) approach was unanimously accepted as a standardized approach endorsed by the Food and Agricultural Organization (Allen et al. 1998; McVicar et al. 2007).

In the context of global warming, the trend of $E T_{\mathrm{o}}$ was found to have increased or decreased in different regions of the world. Increasing trends of $E T_{\mathrm{o}}$ were observed in Iran (Tabari et al. 2011, 2012) and southern Spain (Espadafor et al. 2011). However, a decreasing $E T_{\mathrm{o}}$ trend was reported for India (Chattopadhyay and Hulme 1997). $E T_{\mathrm{o}}$ at many places in China have decreased (see detail in Table 6 from McVicar et al. 2007). Trends in $E T_{\mathrm{o}}$ have decreased in northwest and southeast regions (Thomas 2000), the Yangtze River Basin (Xu et al. 2006), part of the Yellow River Basin (Liu and Yang 2010), Tibet Plateau (Liu et al. 2011), and the Haihe River Basin (Tang et al. 2011). The increase or decrease of $E T_{\mathrm{o}}$ were mainly caused by the increase or decrease of climatic variables $(\mathrm{CVs})$, which are necessary for estimating $E T_{\mathrm{o}}$. These variables include air temperature $(T)$, wind speed $(U)$, relative humidity $(R H)$, and radiation or sunshine hour $(n)$ in the absence of radiation. The influences of CVs on $E T_{\mathrm{o}}$, which also potentially reflect the effects of climatic change on $E T_{\mathrm{o}}$, have been investigated regionally or globally (McVicar et al. 2012; Xu et al. 2006).

There are different ways for assessing the influences of $\mathrm{CVs}$ on $E T_{\mathrm{o}}$. One way is to conduct a sensitivity analysis. This is done by determining the corresponding changes of $E T_{\mathrm{o}}$ after adding 
different percentages of the CVs or by calculating the sensitivity coefficient (Goyal 2004; Lenhart et al. 2002; McKenney and Rosenberg 1993). Because $E T_{\mathrm{o}}$ is a multi-factor parameter, its sensitivity varies with various CVs. Moreover, other factors, such as geological locations and the calculation models, also affect its sensitivity. Another way is to analyze the $E T_{\mathrm{o}}$ series re-estimated by the detrended CVs such as previous studies investigating the influences of detrended CVs on $E T_{\mathrm{o}}$ in the Changjiang River Catchment during 1970-2000 (Xu et al. 2006) and in northwestern China (Huo et al. 2013). However, their results only showed the influences of single CV on $E T_{\mathrm{o}}$, not the simultaneous influences of multiple variables on $E T_{\mathrm{o}}$. Because CVs change simultaneously, even the minimum, mean and maximum $T\left(T_{\min }, T_{\text {ave }}\right.$ and $\left.T_{\max }\right)$ increased with different patterns, not to mention the other CVs. It is not sufficient to only know the influences of single CV on $E T_{\mathrm{o}}$. Previous research has not distinguished the ability of various $T \mathrm{~s}\left(T_{\min }, T_{\mathrm{ave}}\right.$ and $\left.T_{\max }\right)$ on influencing $E T_{\mathrm{o}}$. Moreover, not only removing linear trends from $\mathrm{CVs}$ is executable and referable, but also removing nonlinear trends in $\mathrm{CVs}$ is necessary because most $\mathrm{CVs}$ vary nonlinearly with time. There is limited research that compares the influences of removing linear trends and nonlinear trends from various CVs on $E T_{\mathrm{o}}$.

The effects of climate change on $E T_{\mathrm{o}}$ in northwestern China have been studied by Huo et al. (2013) using data obtained from 23 weather stations. The linear trends of $T, R H$, solar radiation and $U$ were removed, and the detrended CVs were used for re-estimating $E T_{\mathrm{o}}$. Their results showed that the contribution of the decline in $U$ to the decrease in $E T_{\mathrm{o}}$ is larger than that of other meteorological variables. This study investigates the effects of removing linear and nonlinear trends from the annual CVs (including $T_{\min }, T_{\mathrm{ave}}, T_{\max }, R H, U$ and $n$ ) on the temporal variations of annual $E T_{\mathrm{o}}$ in Xinjiang, China. Our aims are to: i) assess the importance of each CV to $E T_{\mathrm{o}}$ for northern (NX), southern (SX) and the entirety of Xinjiang (EX); ii) to compare the differences in removing the 
trends from single, double and multi-CVs in various scenarios for each sub-region, and to distinguish the influences of various $T$-factors $\left(T_{\min }, T_{\text {ave }}\right.$ and $\left.T_{\max }\right)$ and non- $T$-factors $\left(U_{2}, R H\right.$ and $\left.n\right)$ on changing $E T_{\mathrm{o}}$; and iii) to clearly show how the CVs affect $E T_{\mathrm{o}}$ in Xinjiang by comparing the original and recalculated $E T_{\mathrm{o}}$ series using the linear and nonlinear detrended $\mathrm{CV} s$.

\section{Data and Methodology}

\subsection{The study sites and the data sets}

The Xinjiang Uygur Autonomous Region is located in inland area of northwestern China. Xinjiang is surrounded on three sides by mountains and is distant from any sea (Li et al. 2016). The multiyear mean ratio of precipitation $(P)(147 \mathrm{~mm})$ to $E T_{\mathrm{o}}(1512 \mathrm{~mm})$ is 0.1 (Li and Sun 2016); therefore, the region was classified as an arid zone according to Erinç (1965). A total of 53 weather stations in Xinjiang, China were selected as study sites (Figure 1). The observed monthly weather data were collected from the Meteorological Data Sharing Service Network in China, with strict quality control. Elevations of the selected sites ranged between 30-3095 m. The data duration was from 1961 to 2013 with the completeness larger than $99.7 \%$. Missing data were interpolated linearly with the neighboring months. The belt along Tuergate - Aheqi - Bayinbuluke - Urumqi - Qitai Qijiaojing - Balikun - Zhuomaohu, which belongs to NX, was set as the border of NX and SX. There were 27 sites in NX and 26 sites in SX, respectively.

Figure 1

\subsection{Estimation of reference crop evapotranspiration}

The Penman-Monteith equation (Allen et al. 1998) is used here for estimating $E T_{\mathrm{o}}(\mathrm{mm})$ :

$$
E T_{o}=\frac{0.408 \Delta\left(R_{n}-G\right)+\gamma \frac{900}{T_{\text {ave }}+273} U_{2}\left(e_{s}-e_{a}\right)}{\Delta+\gamma\left(1+0.34 u_{2}\right)}
$$

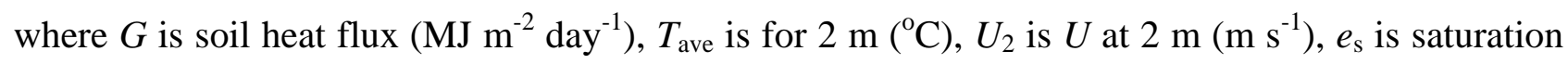


vapor pressure $(\mathrm{kPa}), e_{\mathrm{s}}-e_{\mathrm{a}}$ is saturation vapor pressure deficit $(\mathrm{kPa}), \Delta$ is slope of vapor pressure

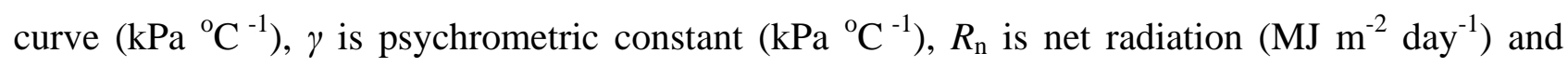
calculated with $n$ following Allen et al. (1998). Monthly $G$ is estimated by

$$
G_{\mathrm{M}}=0.07\left(T_{\mathrm{M}+1}-T_{\mathrm{M}-1}\right)
$$

where the subscripts $M+1, M$ and $M-1$ are the numbers of month. Annual $E T_{\mathrm{o}}$ is determined by monthly values.

\subsection{Trend and abrupt change year analysis}

The data series of the trend and abrupt change year $\left(\mathrm{Y}_{\mathrm{AC}}\right)$ analysis include the $T_{\min }, T_{\mathrm{ave}}, T_{\max }$, $U_{2}, n, R H, P$ and $E T_{\mathrm{o}}$. A trend test is conducted by the modified nonparametric Mann-Kendall (MMK) method (Yue and Wang 2002). The MMK method reflects the effects of autocorrelation in time series $x_{\mathrm{i}}\left(i=1,2, \ldots, N_{\mathrm{T}}\right.$, where $N_{\mathrm{T}}$ is the total year number) based on the Mann-Kendall (MK) method (Kendall 1975; Mann 1945). In order to limit the influence of serial autocorrelation, the original standardized MK test statistic $(Z)$ is modified to the new MMK statistic $\left(Z_{\mathrm{m}}\right)$ with a correction factor $n^{\mathrm{s}}$ ( $\mathrm{Li}$ et al. 2010; Yue and Wang 2002), written as below:

$$
Z_{\mathrm{m}}=Z / \sqrt{n^{s}}, \text { where } n^{s}= \begin{cases}1+\frac{2}{n} \sum_{j=1}^{n-1}(n-1) r_{j} & \text { for } j>1 \\ 1+2 \frac{r_{1}^{n+1}-n r_{1}^{2}+(n-1) r_{1}}{n\left(r_{1}-1\right)^{2}} & \text { for } j=1\end{cases}
$$

where $r_{j}$ is sample auto-correlation coefficient of $x_{\mathrm{i}}$ at lag $j$.

If $Z$ (or $Z_{\mathrm{m}}$ ) is positive (or negative), $x_{\mathrm{i}}$ has an upward (or downward) trend. When the $\operatorname{lag} j$ of autocorrelation functions $r_{\mathrm{j}}$ is $>0$ and $\left|Z_{\mathrm{m}}\right| \geq 1.96$, the trend is significant at a confidence level $\alpha=0.05$, and $x_{\mathrm{i}}$ is time-dependent. The slope of the trend $(b)$ is estimated by the method of Sen (1968).

A sequential Mann-Kendall (SQMK) analysis is used for $\mathrm{Y}_{\mathrm{AC}}$ detection (Partal and Kahya 
2006). The SQMK is a sequential progressive $u(\mathrm{t})$ and backward $u$ ' $(\mathrm{t})$ analyses of the MK test. If the two series cross each other, the crossing point exhibits the $\mathrm{Y}_{\mathrm{AC}}$. If the two series cross and diverge from each other for a longer period of time, the beginning of the year of divergence exhibits the $\mathrm{Y}_{\mathrm{AC}}$. Its sequential behavior fluctuates close to zero. In the sequential progressive $u(\mathrm{t})$ analysis, the number of cases $x_{\mathrm{j}}>x_{\mathrm{K}}(K=1,2, \ldots, j-1)$, denoted by $N_{\mathrm{j}}$, is counted at each comparison. The SQMK test statistic $S_{\mathrm{j}}$ is calculated by

$$
S_{j}=\sum_{j} N_{j}
$$

The mean and variance of the test statistic are calculated by

$$
E(t)=\frac{N_{\mathrm{T}}\left(N_{\mathrm{T}}-1\right)}{4}
$$

and

$$
\operatorname{Var}\left(t_{j}\right)=\frac{j(j-1)(j 2}{72}
$$

Sequential progressive $u(\mathrm{t})$ is calculated by

$$
u(t)=\frac{S_{j}-E(t)}{\sqrt{\operatorname{Var}\left(S_{j}\right)}}
$$

Sequential backward serial values $u^{\prime}(\mathrm{t})$ are calculated similarly with the end of $x_{\mathrm{i}}$ being starting point.

\subsection{Linear and nonlinear detrending approaches of climate variables}

The trends in CVs of $T_{\min }, T_{\text {ave }}, T_{\max }, U_{2}, n, R H$ and $E T_{\mathrm{o}}$ will be analyzed. A linear trend is obtained by linearly correlating $x_{\mathrm{i}}$ with the year. The ensemble empirical mode decomposition (EEMD) (Wu and Huang 2009), an adaptive and temporally local time series analysis method (Ji et al. 2014), is applied to obtain the nonlinear trends in the CVs. Its principle is to obtain the arithmetic mean of multiple observations by adding multiple white noise realizations to the target data to mimic a scenario of multi-trial observations for a single-trial one. After multi-step calculations, the raw data are decomposed into finite intrinsic mode functions and a nonlinear trend. 
A detrended data series $x_{\mathrm{i}, \mathrm{D}}$ is generated by removing the linear or nonlinear trend from an observed time series $x_{\mathrm{i}}$ at each year. Then, a constant value is added to maintain $x_{\mathrm{i}, \mathrm{D}}$ at a similar variation range to $x_{\mathrm{i}}$. For the linear trend analysis, the constant value is the multi-year average of $x_{\mathrm{i}}$. For the nonlinear trend analysis, the constant value is $x_{1}$.

\subsection{Scenarios of $E T_{0}$ estimated using the detrended CVs}

The total number of scenarios is $2\left(C_{6}^{1}+C_{6}^{1}+C_{6}^{1}+C_{6}^{1}+C_{6}^{1}+C_{6}^{1}\right)=114$. Despite all CVs change over a long time-period, and scenarios for different CV scenarios could be as many as 114 considering both linear and non-linear trend removal effects, this research can't cover all. Here we mainly focus on comparing the effects of detrending (i) different temperature-related factors (i.e, $T$-factor, $T_{\min }, T_{\text {ave }}$ and $T_{\max }$ ), and (ii) $T$ - and non- $T$ factors (i.e, $U_{2}, R H$ and $n$ ) on changing $E T_{\mathrm{o}}$. In addition to the original scenario (S-1) of $E T_{\mathrm{o}}$, which is estimated by the observed CVs, 2 scenario groups are set, and both contain 14 different scenarios ('S-' below) of recalculated $E T_{\mathrm{o}}$ using the different combinations of the observed and detrended CVs (Table 1). In Group I (or II), linear (or nonlinear) trends in one or more observed CVs are removed, and the detrended CVs with the other observed CVs are used for recalculating $E T_{\mathrm{o}}$. A total of 29 scenarios of $E T_{\mathrm{o}}$, including $\mathrm{S}-1, \mathrm{~S}-2$ to S-15 in Group I and S-2 to S-15 in Group II, are applied. In scenarios 2 to 8, the effects of detrending single, bi-, or multi- $T$-factors on the recalculated $E T_{\mathrm{o}}$ are compared step by step, while in scenarios 9 to 14 , the effects of detrending single, or two non- $T$-factors are compared step by step. The influence extent between $T$ - and non- $T$-factors could be shown by comparing scenarios 2 to 8 with scenarios 9 to 14 indirectly.

Table 1

\section{Results}

\subsection{Temporal variations of CVs and $E T_{0}$ and their trends}


The temporal variations of annual CVs and their linear and nonlinear trends in NX, SX and EX over 1961-2013 are illustrated in Figure 2. The CVs differed between NX and SX, with the Tianshan Mountains as a division. Although the fluctuation patterns of $T_{\min }, T_{\text {ave }}, T_{\max }, U_{2}$ and $R H$ between NX and SX were generally similar, distinctively different ranges were shown. $T_{\min }, T_{\text {ave }}$ and $T_{\max }$ were higher but $U_{2}$ and $R H$ were lower in SX than in NX. However, this was not the case for $n$, which had generally similar ranges for NX, SX and EX. The CV values in EX were between those in NX and SX. There were general increases in $T_{\min }, T_{\text {ave }}$ and $T_{\max }$ but decreases in $U_{2}$ and $n$ in $\mathrm{NX}, \mathrm{SX}$ and EX, as shown by the linear trends. $R H$ had very weak increasing trends either in NX, SX or EX. The linear trends of $T_{\min }, T_{\text {ave }}$ and $T_{\max }$ after 1976 were generally similar to their nonlinear trends. However, the linear trends of $T_{\min }, T_{\text {ave }}$ and $T_{\max }$ before 1976 and $U_{2}, R H$ and $n$ over the whole study period were generally different from their nonlinear trends. These differences would result in different recalculated $E T_{\mathrm{o}}$ in Groups I and II.

Figure 2

The nonlinear variations of $U_{2}, R H$ and $n$ contributed greatly to the nonlinear variations of $E T_{\mathrm{o}}$. The different fluctuations of the six observed $\mathrm{CV}$ s resulted in corresponding differences of $E T_{\mathrm{o}}$ between NX, SX and EX (Figure 3). There were similar fluctuations of $E T_{\mathrm{o}}$ in NX, SX and EX, but the $E T_{\mathrm{o}}$ values in NX were generally smaller than those in SX for the entire study period. Similar values between $E T_{\mathrm{o}}$ in NX and EX than between SX and EX were observed. $E T_{\mathrm{o}}$ showed decreased linear trends but concave nonlinear and non-monotone trends with a sub-region order of $\mathrm{SX}>\mathrm{EX}>\mathrm{NX}$. The difference between the linear and nonlinear $E T_{\mathrm{o}}$ trends for each sub-region was prominent, which would cause differences between the subsequent regenerated $E T_{\mathrm{o}}$ scenarios between Groups I and II. 
The tested trends and abrupt change years, $Y_{\mathrm{AC}}$, for the annual CVs and $E T_{\mathrm{o}}$ are presented in Table 2. The calculated sequential progressive $u(\mathrm{t})$ and backward $u^{\prime}(\mathrm{t})$ curves are illustrated in Figure 4, from which the $Y_{\mathrm{AC}}$ could be visually discerned for each CV and sub-region. At the annual timescale, $T_{\min }$ increased significantly in NX and EX but insignificantly in $\mathrm{SX} ; T_{\max }$ increased significantly in NX but insignificantly in SX and EX; $U_{2}$ decreased but $T_{\text {ave }}$ and $R H$ increased, all insignificantly in NX, SX and EX; $n$ decreased insignificantly in NX and EX but significantly in SX; and $P$ increased insignificantly in NX and EX but significantly in SX. Under the interactions of the different CVs, annual $E T_{\mathrm{o}}$ decreased insignificantly in NX, SX and EX. Sen's slope $b$ had an order of $T_{\min }>T_{\mathrm{ave}}>T_{\max }$ for each sub-region. The values of $b$ for the six CVs and $E T_{\mathrm{o}}$ differed slightly, but there were large differences for $b$ values of $P$ in different sub-regions. The sign of $b$ agreed well with that of $Z_{\mathrm{m}}$. The tested $Y_{\mathrm{AC}}$ happened in 1992 or 1993 for $T_{\min }$, in 1993 or 1996 for $T_{\text {ave }}$, and in 1996 and 1997 for $T_{\max }$ for different sub-regions. The $Y_{\mathrm{AC}}$ in each sub-region had a $\mathrm{CV}$ order of $T_{\min }<T_{\text {ave }}<T_{\max }$. The $Y_{\text {AC }}$ of $U_{2}$ occurred in 1980, 1977 and 1978 for NX, SX and EX, respectively. The $Y_{\mathrm{AC}}$ of $R H$ was in 1974 for NX and 1975 for SX. The $Y_{\mathrm{AC}}$ of $n$ was in 1978 for NX and 1971 for EX. No abrupt change occurred for $R H$ in EX and for $n$ in SX. The $Y_{\mathrm{AC}}$ of $P$ occurred in 1986 and 1987. The $Y_{\mathrm{AC}}$ of $E T_{\mathrm{o}}$ were in 1979, 1975 and 1975 for NX, SX and EX, respectively. Overall, the climate change in Xinjiang was warmer and wetter in the recent 53 years.

-Table 2

Figure 4

The Pearson correlation coefficients $(r)$ shows the statistical relationship between annual $E T_{\mathrm{o}}$ and each related $\mathrm{CV}$ as well as the relative contribution of each $\mathrm{CV}$ to $E T_{\mathrm{o}}$ for NX, SX and EX (Table 3). The $r$ values were positive for $E T_{\mathrm{o}}$ with $T_{\min }, T_{\text {ave }}, T_{\max }, U_{2}$ and $n$, but negative for $E T_{\mathrm{o}}$ with $R H$ in NX, and negative for $E T_{\mathrm{o}}$ to $T_{\min }, T_{\mathrm{ave}}$ and $R H$ in $\mathrm{SX}$ and $\mathrm{EX}$ at different significant 
levels. The absolute $r$ values for $E T_{\mathrm{o}}$ with $R H$ and $n$ in NX were larger than 0.5 , which implied that from a statistical viewpoint, $R H$ and $n$ were the main factors that influenced $E T_{\mathrm{o}}$ in $\mathrm{NX}$. The absolute $r$ values for $E T_{\mathrm{o}}$ with $T_{\max }$ and $U_{2}$ in NX were 0.438 and 0.395 , respectively, indicating the two next important factors that affected $E T_{\mathrm{o}}$ in NX. In SX and EX, the absolute $r$ values for $E T_{\mathrm{o}}$ with $U_{2}, R H$ and $n$ were larger than 0.5 . The absolute $r$ values for $E T_{\mathrm{o}}$ with $T_{\min }, T_{\text {ave }}$ and $T_{\max }$ were much smaller than for $E T_{\mathrm{o}}$ with the other $3 \mathrm{CVs}$ in $\mathrm{NX}$, SX or EX. The absolute $r$ values were used to rank the CVs to primarily and statistically assess the extent of their influence on $E T_{\mathrm{o}}$. The ranks of $\mathrm{CVs}$ were $R H>n>T_{\max }>U_{2}>T_{\mathrm{ave}}>T_{\min }$ for $\mathrm{NX}, U_{2}>n>R H>T_{\min }>T_{\mathrm{ave}}>T_{\max }$ for $\mathrm{SX}$, and $n>R H>U_{2}>T_{\max }>T_{\min }>T_{\text {ave }}$ for EX. The generally larger roles of $U_{2}$ and $n$ (with decreasing trends), as well as $R H$ (with slightly increasing trends) than $T_{\min }, T_{\text {ave }}$ and $T_{\max }$ on $E T_{\mathrm{o}}$ may have contributed to the decreasing trends of $E T_{\mathrm{o}}$ over 1961-2013 in Xinjiang, China.

Table 3

The $r$ values for $E T_{\mathrm{o}}$ with the related six CVs were only shown for S-1 in Table $3 ; r$ for $E T_{\mathrm{o}}$ with the CVs in the other scenarios were not shown. The above results can be referenced in the other scenarios. In addition, although the $Y_{\mathrm{AC}}$ was detected for the CVs over 1961-2013, these values were only for primary investigations of their temporal variation characteristics. The following trend removal analysis of each $\mathrm{CV}$ would not be conducted in two (or more) time stages using the $Y_{\mathrm{AC}}$ as a division because there were only 53 years of this short study period. The nonlinear trends showed generalized temporal changes in the CVs, which also reflected the $Y_{\mathrm{AC}}$ to some extent.

There was a $\mathrm{CV}$ order affecting $E T_{\mathrm{o}}$ for each sub-region through correlation analysis. This order only showed the possible effects of $\mathrm{CV}$ on $E T_{\text {o, }}$, which were static. When the correlation was conducted for scenario I, the static roles of each $\mathrm{CV}$ on $E T_{\mathrm{o}}$ was shown. When scenarios changed, 
the static roles of each $\mathrm{CV}$ on $E T_{\mathrm{o}}$ changed because the detrended $\mathrm{CV}$ s would be applied to correlate with detrended $E T_{\mathrm{o}}$. Correlation analysis between the recalculated $E T_{\mathrm{o}}$ and CVs were not conducted for scenarios II to XV because correlation analysis after detrending only reflected shared time series variation independent of any underlying trend. The correlation analysis only showed the connect extent between $E T_{\mathrm{o}}$ and $\mathrm{CVs}$ from a statistical respect. When also considering the shared trend of each $\mathrm{CV}$, its effects could be shown more clearly. It should be emphasized that when a slight trend occurs in the CVs, e.g., for $n$, its effects on changing $E T_{\mathrm{o}}$ could be also slight for investigating detrending effects on $E T_{\mathrm{o}}$, although its $r$ values with $E T_{\mathrm{o}}$ is relatively high.

\subsection{Effects of removing linear trends from the CVs on $E T_{0}$}

The recalculated $E T_{\mathrm{o}}$ series using the linearly detrended CVs in various scenarios of Group I over 1961-2013 are compared with S-1 (Figure 5). In Figure 5a of the recalculated values of $E T_{\mathrm{o}}$ for NX, the $E T_{\mathrm{o}}$ curves of S-2 (in which $T_{\min }$ was detrended) and S-4 ( $T_{\max }$ was detrended) decreased, but that of S-3 ( $T_{\text {ave }}$ was detrended) increased slightly when compared to S-1. Larger differences existed after 2000. This caused the actual roles of increasing $T_{\min }, T_{\text {ave }}$ and $T_{\max }$ on $E T_{\mathrm{o}}$ to differ. Although the trends in $T_{\min }, T_{\text {ave }}$ and $T_{\max }$ were all increasing, the increase of $T_{\text {ave }}$ decreased $E T_{\mathrm{o}}$ very slightly, whereas both the increases of $T_{\min }$ and $T_{\max }$ increased $E T_{\mathrm{o}}$. The increase of $T_{\min }$ on increasing $E T_{\mathrm{o}}$ surpassed that of $T_{\max }$, because the Sen's slope of $T_{\min }$ (Table 2) was larger than that of $T_{\max }$ for each sub-region. For SX (Figure 5aa) and EX (Figure 5aaa), small differences were found between the $E T_{\mathrm{o}}$ curves of S-1 and S-3 and between S-2 and S-4. There were greater effects of detrending $T_{\min }$ and $T_{\max }$ than detrending $T_{\text {ave }}$ on changes in $E T_{\mathrm{o}}$ in $\mathrm{SX}$ and EX. In Figure $5 \mathrm{~b}$ of the recalculated values of $E T_{\mathrm{o}}$ for $\mathrm{NX}$, there were general decreases in $E T_{\mathrm{o}}$ when the increasing trends in two or three of $T_{\min }, T_{\text {ave }}$ and $T_{\max }$ were removed. Their decreasing effects on $E T_{\mathrm{o}}$ ranked in a CV order of $\left(T_{\text {ave }} \& T_{\max }\right)<\left(T_{\min } \& T_{\text {ave }}\right)<\left(T_{\min }, T_{\text {ave }} \& T_{\max }\right)<\left(T_{\min } \& T_{\max }\right)$, corresponding to a 
scenario order of $S-7<S-5<S-8<S-6$. However, the differences between various scenarios were small.

For SX (Figure 5bb) and EX (Figure 5bbb), the $E T_{\mathrm{o}}$ curve of S-5 were very close to that of S-7, and the $E T_{\mathrm{o}}$ curve of S-6 were close to that of S-8. All four curves were below the $E T_{\mathrm{o}}$ curve of S-1, showing the effects of detrending multi- $T$-factors on decreasing $E T_{\mathrm{o}}$. These decreasing effects on $E T_{\mathrm{o}}$ ranked with a $\mathrm{CV}$ order of $\left(T_{\mathrm{ave}} \& T_{\max }\right)\left(\right.$ or $\left.T_{\min } \& T_{\mathrm{ave}}\right)<\left(T_{\min } \& T_{\max }\right)\left(\right.$ or $\left.T_{\min }, T_{\mathrm{ave}} \& T_{\max }\right)$, corresponding to a scenario order of S-5(or S-7) $<$ S-6 (or S-8) $<$ S-1. Therefore, the increases in $T_{\min }$, $T_{\text {ave }}$ and $T_{\max }$ should have played some role in increasing $E T_{\mathrm{o}}$ in Xinjiang in the recent period of 53 years.

In Figures 5c, 5cc and 5ccc, the effects of removing the decreasing trend of $U_{2}$ in S-9 increased $E T_{\mathrm{o}}$ apparently, while the effects of removing the decreasing trends of $n$ in S-10 or removing small increasing trends of $R H$ in S-11 increased $E T_{\mathrm{o}}$ very slightly in NX, SX and EX. Provided there was no any decrease trend in $U_{2}, E T_{\mathrm{o}}$ should have increased over the past 53 years. This also explained why the influences of detrending $U_{2} \& R H$ in S-13 and detrending $U_{2} \& n$ in S-14 surpassed that of detrending $n \& R H$ in S-12 on increasing $E T_{\mathrm{o}}$ (Figures 5d, 5dd and 5ddd). In addition, the effects of increasing $U_{2}$ on decreasing $E T_{\mathrm{o}}$ were much stronger than that of increasing $T_{\min }, T_{\text {ave }}$ and $T_{\max }$ on increasing $E T_{\mathrm{o}}$. Overall, the effects of removing all the trends from the six CVs $(\mathrm{S}-15)$ caused the increases of $E T_{\mathrm{o}}$ in NX, SX and EX over 1961-2013. Provided without any trend in each CV, $E T_{\mathrm{o}}$ should have increased over the past 53 years.

Figure 5

\subsection{Effects of removing nonlinear trends from the CVs on $E T_{0}$}

The recalculation of $E T_{\mathrm{o}}$ by removing the nonlinear trends from the $\mathrm{CVs}$ for the 14 scenarios of Group II over 1961-2013 are shown in Figure 6. It also shows the effects of removing the 
increasing trends in $T_{\min }, T_{\mathrm{ave}} \& T_{\max }$ on slight decreasing or increasing $E T_{\mathrm{o}}$, removing decreasing trends in $U_{2}$ on largely increasing $E T_{\mathrm{o}}$, removing the slight decreasing trend of $n$ on tiny increasing $E T_{\mathrm{o}}$, and removing the increasing trend of $R H$ on minute increasing $E T_{\mathrm{o}}$ in each sub-region. The effects of detrending two, three or all CVs were connected with that of detrending a single CV on changes in $E T_{\mathrm{o}}$. Similar to Group I, the effects of detrending $U_{2}, n$ and $R H$ on increasing $E T_{\mathrm{o}}$ also surpassed the effects of detrending $T_{\min }, T_{\text {ave }} \& T_{\max }$ on decreasing $E T_{\mathrm{o}}$ for Group II, which resulted in a general increase of $E T_{\mathrm{o}}$ after removing all the trends from the six CVs.

Figure 6

The results from Groups I and II explained why the actual $E T_{\mathrm{o}}$ decreased over the studied period. The recalculated $E T_{\mathrm{o}}$ in Groups I and II generally varied in similar patterns but with different scopes and values. Figures 5 and 6 showed temporal fluctuations of the recalculated $E T_{\mathrm{o}}$ in different scenarios, but the $r$ values in Table 3 only showed statistical (static) correlations between $E T_{\mathrm{o}}$ and the CVs in $\mathrm{S}-1$. The combined methods revealed the relationship between $E T_{\mathrm{o}}$ and the CVs from two different respects.

\section{4 $D_{\text {ETo }}$ variations for different scenarios of Groups I and II}

There are differences between the $E T_{\mathrm{o}}$ values of the various scenarios and S-1 $\left(D_{\mathrm{ETo}}\right)$. Figure 7

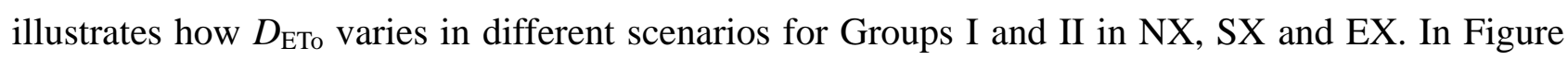
7a of Group I in NX, the four $D_{\mathrm{ETo}}$ curves, in which the $E T_{\mathrm{o}}$ values were recalculated using the detrended $U_{2}(\mathrm{~S}-9)$, the detrended $U_{2} \& R H(\mathrm{~S}-12)$, the detrended $U_{2} \& n(\mathrm{~S}-14)$, and the detrended six CVs (S-15), were generally positive and larger than the $D_{\mathrm{ETo}}$ values of the other 10 scenarios over 1961-2013. These four $D_{\mathrm{ETo}}$ curves showed larger recalculated $E T_{\mathrm{o}}$ values than original $E T_{\mathrm{o}}$ values in S-1 over time. The total $D_{\text {ETo }}$ reached 72.8 for S-14, 72.3 for S-9, 68.3 for S-12 and 36.2 for S-15 mm in 2013, respectively. The increases of the four $D_{\text {ETo }}$ curves generally followed a 
scenario order of S-9>S-14>S-12>S-15. On the contrary, the other four $D_{\mathrm{ETo}}$ curves, in which $E T_{\mathrm{o}}$ values were recalculated using the detrended $T_{\min } \& T_{\max }(\mathrm{S}-6)$, the detrended $T_{\min }, T_{\mathrm{ave}} \& T_{\max }(\mathrm{S}-8)$, the detrended $T_{\min }(\mathrm{S}-2)$ and the detrended $T_{\min } \& T_{\text {ave }}(\mathrm{S}-5)$, decreased over time. The decreases of $D_{\text {ETo }}$ curves ranked in a scenario order of S-5<S-2<S-8<S-6, and the total $D_{\text {ETo }}$ in 2013 reached $-18.9,-20.2,-28.4$ and $-28.0 \mathrm{~mm}$, respectively. The other six $D_{\text {ETo }}$ curves in S-3, S-4, S-7, S-10, S-11 and S-13 decreased a little over time, and their absolute $D_{\text {ETo }}$ values in 2013 were all below 7.8 $\mathrm{mm}$. Therefore, there were generally three types of $D_{\mathrm{ETo}}$ curves that resulted from detrended $U_{2}$ (or $U_{2}$ and $R H$ or $n$ ), detrended $T_{\min }, T_{\text {ave }} \& T_{\max }$, and detrended $R H$ and $n$, respectively. These three types were also typical for the $D_{\text {ETo }}$ curves in SX (Figure $7 \mathrm{~b}$ ) and EX (Figure 7c), although the orders of scenarios for increased or decreased $D_{\mathrm{ETo}}$ changed within each type. There were even larger $D_{\mathrm{ETo}}$ curves of S-14, S-9, S-12 and S-15 in SX than in NX. The $D_{\mathrm{ETo}}$ curves of various scenarios in EX were between those of NX and SX.

For Group II (Figures 7aa, 7bb and 7cc), the $D_{\text {ETo }}$ values increased (e.g., in S-9, S-14 and S-12), increased first and then decreased (in S-15), or decreased (in the other 10 scenarios of recalculated $E T_{\mathrm{o}}$ ) over time, and the variations of $D_{\mathrm{ETo}}$ values had a general sub-region order of $\mathrm{SX}>\mathrm{EX}>\mathrm{NX}$. The main differences of $D_{\mathrm{ETo}}$ curves between Groups I and II was that the $D_{\mathrm{ETo}}$ values in the 14 scenarios of Group I generally increased linearly (although had some perturbations) as time increased, but most $D_{\text {ETo }}$ curves in Group II varied nonlinearly, they increased before 1996 but decreased after the year. This differed with the effects of linear or nonlinear trend removal from the CVs on the changes in $E T_{\text {o }}$. Therefore, in Group I, especially for S-9, S-12, S-14 and S-15, the $D_{\text {ETo }}$ curves increased to larger values than those in Group II until 2013.

- Figure 7

Figure 8 shows the statistical properties of $D_{\mathrm{ETo}}$ for 14 scenarios of Groups I and II in NX, SX 
and EX. In Figure 8a, the minimum $D_{\text {ETo }}$ values ranged between -40 and $14 \mathrm{~mm}$ for different scenarios, of which S-6 (detrending $T_{\min } \& T_{\max }$ ) and S-8 (detrending $T_{\min }, T_{\text {ave }} \& T_{\max }$ ) had the smallest minimum $D_{\text {ETo }}$ in NX, SX and EX. The effects of detrending $T$-related-factors have surpassed that of detrending non- $T$-related-factors on decreasing the minimum $D_{\mathrm{ETo}}$. For NX, the minimum $D_{\text {ETo }}$ values from S-2 to S-8 in Group I were smaller than those in Group II but reversed for the other six scenarios. For SX and EX, the minimum $D_{\mathrm{ETo}}$ values from $\mathrm{S}-2$ to $\mathrm{S}-8$ in Group I were larger than those values in Group II. In Figure 8b, the average $D_{\text {ETo }}$ values ranged between -18 and $57 \mathrm{~mm}$ for different scenarios. Generally, the average $D_{\mathrm{ETo}}$ values were negative for S-2 to S-8 but positive for S-9 to S-15, of which, S-9, S-12, S-14 and S-15 had much larger average $D_{\text {ETo }}$ values than the other 11 scenarios, showing the strong effects of detrending $U_{2}$ (or $U_{2}$ with $R H$ and $n$ ) on increasing the average $D_{\mathrm{ETo}}$. In Figure $8 \mathrm{c}$, the differences among the maximum $D_{\mathrm{ETo}}$ values of various scenarios were even more prominent than the minimum and average $D_{\text {ETo }}$ values. Similar to average $D_{\mathrm{ETo}}$, the maximum $D_{\mathrm{ETo}}$ values were much larger for S-9, S-12, S-14 and S-15 (ranging from 40 to $118 \mathrm{~mm}$ ) than for the other 11 scenarios (ranging from -5 to $20 \mathrm{~mm}$ ). The maximum $D_{\text {ETo }}$ curves generally ranked with an order of "SX in Group II $>$ EX in Group II $>$ SX in Group I $>$ EX in Group I $>$ NX in Group I $>$ NX in Group II". Overall, the minimum $D_{\text {ETo }}$ values were small and negative, the average $D_{\text {ETo }}$ values varied in a larger scope than the minimum $D_{\text {ETo }}$ values, and the maximum $D_{\mathrm{ETo}}$ values were generally positive and higher than the average and the minimum values. This implied that the trend removals from the CVs changed extreme values, especially the maximum values of $E T_{\mathrm{o}}$ in Xinjiang.

- Figure 8

\subsection{Comparisons of $E T_{0}$ after trend removals from all of the six CVs}

The $E T_{\mathrm{o}}$ values of $\mathrm{S}-1$ were generally smaller than the recalculated $E T_{\mathrm{o}}$ values of $\mathrm{S}-15$ after 
removing all the linear (Group I) or nonlinear (Group II) trends from all of the six CVs over the period 1961-2013 in NX, SX and EX (Figure 9). There were larger differences in $E T_{\mathrm{o}}$ curves of S-15 for Groups II than for Group I over 1961-2010 for NX, and over 1961-2005 for SX and EX, respectively, using S-1 as the reference. It was shown that if there was no trend in the CVs, the annual $E T_{\mathrm{o}}$ should have been larger than the actual values over 1961-2013 in Xinjiang. $E T_{\mathrm{o}}$ in Xinjiang responded prominently to the changes in climate.

Figure 9

\subsection{Different detection technologies that affect $E T_{0}$ trends}

Li et al. (2014) reported that the change of dominant factors in the $E T_{\mathrm{o}}$ trend has differences after 1993, and judged a $Y_{\mathrm{AC}}$ of 1993 by comparing the $E T_{\mathrm{o}}$ anomaly in northwestern China including Xinjiang. From our results, the $Y_{\mathrm{AC}}$ for NX, SX and EX happened in 1979, 1975 and 1975, respectively, which were earlier than the reported 1993 of Li et al. (2014). Our results were obtained using the SQMK change point analysis, which detected the $Y_{\mathrm{AC}}$ statistically. Figure 10 clearly shows the decadal averages and the periodical linear trends in $E T_{\mathrm{o}}$ for EX. In any case, both the decadal average and periodical linear lines showed that there were more than one $Y_{\mathrm{ACS}}$ over 1961-2013 in Xinjiang. Owing to the limitations of the method, the SQMK technique may have only detected the first significant $Y_{\mathrm{AC}}$ in the $E T_{\mathrm{o}}$ series in the study period, while the $E T_{\mathrm{o}}$ anomaly technique (Li et al. 2014) detected the most significant $Y_{\mathrm{AC}}$. Different results were used for different research aims. Although $Y_{\mathrm{AC}}$ in this research was different from that of Li et al. (2014), it was only used to indicate the temporal variations of $E T_{\mathrm{o}}$ in Xinjiang, and the results didn't affect the further detrending analysis.

Figure 10

\subsection{Consequences of decreased $E T_{\mathrm{o}}$ under global warming}


The decrease of $E T_{\mathrm{o}}$ in Xinjiang, China will result in different consequences for agriculture, hydrology, meteorology, society and the economy. There will be a smaller requirement of irrigation amounts corresponding to the decrease in $E T_{\mathrm{o}}$ and actual evapotranspiration (which could be estimated by multiplying $E T_{\mathrm{o}}$ with a crop coefficient) for field crops and plants. Decreased $E T_{\mathrm{o}}$ and evapotranspiration would result in increased runoff, considering the increased $P$ over the period of 1961-2013 (Li and Sun 2016). Consequently, it could possibly increase the risk of flooding in the summer when the snow on the alpine mountain areas melts rapidly under high temperatures.

$E T_{\mathrm{o}}$ is used as a component of the aridity index $I_{\mathrm{A}}$, which is the ratio of $P$ to $E T_{\mathrm{o}}$ (Budyko 1974; Li et al. 2016). $I_{\mathrm{A}}$ falls in the ranges of $(0.05,0.2),[0.2,0.5),[0.5,0.65),[0.65,0.8),[0.8,1.0)$ and $[1.0,2.0)$ for arid, semi-arid, dry sub-humid, semi-humid, humid and severe humid climates, respectively. Annual $I_{\mathrm{A}}$ values were estimated here for assessing the dry/wet conditions by using different $E T_{\mathrm{o}}$ values obtained from the observed (S-1), the linearly detrended (S-15 in Group I) and the nonlinearly detrended six CVs (S-15 in Group II) in NX, SX and EX, respectively (Figure 10). Generally, there were slightly larger $I_{\mathrm{A}}$ values estimated using $E T_{\mathrm{o}}$ in $\mathrm{S}-1$ than $I_{\mathrm{A}}$ values estimated by using the $E T_{\mathrm{o}}$ values in S-15 of Groups I and II over 1961-2013 in NX, SX and EX. This indicated (i) wetter conditions or relieved droughts in the region under the present global warming background, and (ii) drier conditions after detrending all of the six CVs and reassessing drought conditions. The larger $I_{\mathrm{A}}$ values implied decreased amounts of irrigation would be needed for crops. In this respect, a water crisis would be prevented in the region when only the effects of climate change are considered but the effects of human activity are not considered, which consequently results in more stable economic development to a certain extent, and therefore, a more stable life and society. 


\section{Discussion}

The Sen's slope $(b)$ was used to estimate the trend magnitude. However, for linear detrending, a parametric method was applied which may not be suitable for the data with a non-normal distribution. To clearly investigate their similarity (or differences), Figure 12 quantifies and compares the differences between $b$ and linear slope (LS) values of the related CVs. For most sites or sub-regions, LS values were close to $b$ values for each CV. The deviations between $b$ and LS values were small for different sites or sub-regions. There were two individual data-points in Figures 1a and 1d which deviated more than the other data-points, both occurred for the site Qijiaojing, where there was an infrastructure disturbance (station-moving in 1998, although not far away, $T$ and $U_{2}$ both increased). The linear correlations showed very high similarity of $b$ and LS values either for different sites or sub-regions $\left(0.971<R^{2}<0.993\right)$. For each $\mathrm{CV}$, there were general very similar values of ranges, average, standard error (SD) for LS and $b$, and the root mean square error (RMSE) values were also small (Table 4). Although the Sen's slope estimator is non-parametric and the regression slope method a parametric method, both methods are linear. Therefore, the very slight differences between $L S$ and $b$ values (especially for NX, SX and EX) would led to very similar results for analyzing detrending effects on $E T_{\mathrm{o}}$ and confirmed the correctness of using LS values to detrend CVs.

Figure 12

Table 4

Except scenario 15 , there are no other preset scenarios combining $T$-factor with non- $T$-factor because our results showed that: (1) The effects of simultaneously detrending the three $T$-factors on decreasing $E T_{\mathrm{o}}$ were the largest when compared to the effects of detrending single or two $T$-factors; (2) The effects of detrending $U_{2}$ on increasing $E T_{\mathrm{o}}$ was much larger than detrending $R H$, $n$, or single, 
bi-, or multi- $T$-factors, which emphasized the most important role of $U_{2}$ on changing $E T_{\mathrm{o}}$. It was unnecessary to add extra scenarios to show the detrending effects of combining single, bi-, or multi-Ts with $R H$ or $n$ because their effects on changing $E T_{\mathrm{o}}$ would be small. Therefore, the scenario (S-15) containing both $\mathrm{CVs}$ of multi-Ts and $U_{2}$ could comprehensively show the detrending $\mathrm{CV}$ effects on changing $E T_{\mathrm{o}}$.

With global warming, decreasing trends in $E T_{\mathrm{o}}$ were detected not only in this research for Xinjiang, but also in other studies for many regions in China and around the world. Li et al. (2014) reported that the decreases in the diurnal $T$ range and $U$ may have led to a decrease of $E T_{\mathrm{o}}$ during 1956-1993 in northwestern China, including Xinjiang. Using data from 65 stations over 1954-1993 in China, Thomas (2000) indicated that $E T_{\mathrm{o}}$ had decreased in all seasons, and for south of $35^{\circ} \mathrm{N}, n$ was most strongly associated with changes in $E T_{\mathrm{o}}$, while $U, R H$ and $T_{\max }$ were the primary factors in northwest, central and northeast China, respectively. Gao et al. (2006) found that $n, U$ and $R H$ had greater impacts on $E T_{\mathrm{o}}$ than $T$ over 1956-2000, and the declining tendencies of $n$ and/or $U$ were the major causes for the negative trend of $E T_{\mathrm{o}}$ in most areas of China. Yin et al. (2010) applied a sensitivity analysis to $E T_{\mathrm{o}}$ using data from 595 meteorological stations across China over 1961-2008 and concluded that the decreasing trend of $E T_{\mathrm{o}}$ was primarily driven by a significant decline in $U$, especially in the northwest arid region. Huo et al. (2013) investigated temporal variations in $E T_{\mathrm{o}}$ after linearly detrending the CVs over 1955-2008 in northwest China, including Xinjiang. They also found that the contribution of $U$ to the decrease of $E T_{\mathrm{o}}$ was larger than that of other CVs.

The previous studies generally agreed on emphasizing the importance of the decreased $U$ on decreasing $E T_{\mathrm{o}}$. Our results of the original and the recalculated $E T_{\mathrm{o}}$ values obtained with either linear or nonlinear detrended CVs in Xinjiang also supported this conclusion. Although the 
correlations between $E T_{\mathrm{o}}$ and $n$ or between $E T_{\mathrm{o}}$ and $R H$ were large (absolute $r>0.5$ ) in Xinjiang, their influences on the changes in $E T_{\mathrm{o}}$ were small. This was mainly due to the results that the actual trend slopes in $n$ and $R H$ were small, being only $-0.007 \mathrm{~h} /$ year and $0.024 \% /$ year for EX, respectively.

By comparing the effects of removing linear nonlinear trends from the CVs on $E T_{\mathrm{o}}$ in Xinjiang, differences were found for the recalculated $E T_{\mathrm{o}}$ scenarios between Groups I and II. Because of the non-monotone variations of the CVs and $E T_{0}$, the results from Group II were more convincing for the assessment of the effects of climate change on $E T_{\mathrm{o}}$.

\section{Conclusion}

The climatic factors that drive $E T_{\mathrm{o}}$ have been investigated in parts of or all of China, but the effects of removing linear and nonlinear trends from the related CVs on $E T_{\mathrm{o}}$ have not been conducted before in Xinjiang, China. A total of 29 scenarios, including the non-detrended $E T_{\mathrm{o}}$ scenario (S-1), the recalculated $E T_{\mathrm{o}}$ scenarios in Groups I (by removing linear trends from single or more $\mathrm{CVs}$ ) and II (by removing nonlinear trends from the related $\mathrm{CVs}$ ), were set to analyze how the CVs affected $E T_{\mathrm{o}}$ over 1961-2013 in Xinjiang. Among the six CVs, $U_{2}$ was the most important factor that affected $E T_{\mathrm{o}}$ in NX, SX and EX because $E T_{\mathrm{o}}$ increased the most when $U_{2}$ was detrended either linearly in Group I or nonlinearly in Group II. A decrease in $U_{2}$ caused a general decrease of $E T_{\mathrm{o}}$, which masked the effects of increased $T_{\min }, T_{\mathrm{ave}} \& T_{\max }$ on increasing $E T_{\mathrm{o}}$. The decreases of $n$ and a slight increase of $R H$ also contributed to the tiny decrease of $E T_{\mathrm{o}}$. The different roles of the CVs caused the overall decrease of $E T_{0}$. The statistical properties, including the minimum, the average and the maximum $D_{\mathrm{ETo}}$, were generally within the scopes of -40 to $14 \mathrm{~mm},-18$ to $57 \mathrm{~mm}$, and -5 to $118 \mathrm{~mm}$, respectively.

The effects of simultaneously removing the existed trends in $U, T_{\min }, T_{\text {ave }}, T_{\max }, n$ and $R H$ on 
increasing $E T_{\mathrm{o}}$ were more significant for Group I than for Group II in NX, SX and EX. However, the results from Group II were more convincing than those from Group I because $E T_{\mathrm{o}}$ in Xinjiang exhibited non-monotone variations and changes in trends at different time stages. The thorough step-by-step comparisons of removing trends from single or multiple CVs (either linearly or nonlinearly) on changing $E T_{\mathrm{o}}$ explained why $E T_{\mathrm{o}}$ decreased in Xinjiang under global warming conditions. Consequently, the annual aridity index $I_{\mathrm{A}}$ increased, which indicated wetter conditions in Xinjiang. A water utilization crisis would be relieved slightly considering the decrease of $E T_{\mathrm{o}}$.

\section{Acknowledgements}

This research is financially supported by the China National Science Foundations (51579213, U1203182), and the China 111 project (B12007). The Meteorological Data Sharing Service Network in China supplied the weather data. The constructive comments of anonymous reviewers strengthened the analyses of this paper.

\section{References}

Allen, R.G., Pereira, L.S., Raes, D. and Smith, M., 1998. Crop evapotranspiration-Guidelines for computing crop water requirements. FAO Irrigation and drainage paper 56, Roma, Italia: FAO.

Blaney, H. and Criddle, W., 1952. Determining water requirements in irrigated areas from climatological and irrigation data. USDA, SCS. SCS-TP-96, 48.

Budyko, M.I., 1974. Climate and life. Academic Press, Orlando, FL, 508 pp.

Chattopadhyay, N. and Hulme, M., 1997. Evaporation and potential evapotranspiration in India under conditions of recent and future climate change. Agricultural and Forest Meteorology, 87(1): 55-73.

Erinç, S., 1965. An attempt on precipitation efficiency and a new index. Istanbul University 
Institute Release, Baha Press, Istanbul (in Turkish).

Espadafor, M., Lorite, I., Gavilán, P. and Berengena, J., 2011. An analysis of the tendency of reference evapotranspiration estimates and other climate variables during the last 45 years in Southern Spain. Agricultural Water Management, 98(6): 1045-1061.

Gao, G., Chen, D., Ren, G., Chen, Y. and Liao, Y., 2006. Spatial and temporal variations and controlling factors of potential evapotranspiration in China: 1956-2000. Journal of Geographical Sciences, 16(1): 3-12.

Goyal, R., 2004. Sensitivity of evapotranspiration to global warming: a case study of arid zone of Rajasthan (India). Agricultural Water Management, 69(1): 1-11.

Hargreaves, G.H. and Samani, Z.A., 1985. Reference crop evapotranspiration from temperature. Applied Engineering in Agriculture, 1(2): 96-99.

Huo, Z., Dai, X., Feng, S., Kang, S. and Huang, G., 2013. Effect of climate change on reference evapotranspiration and aridity index in arid region of China. Journal of Hydrology, 492: 24-34.

IPCC, 2013. Working Group I Contribution to the IPCC Fifth Assessment Report, Climate Change 2013: The Physical Science Basis: Summary for Policymakers.

Ji, F., Wu, Z., Huang, J. and Chassignet, E.P., 2014. Evolution of land surface air temperature trend. Nature Climate Change, 4(6): 462-466.

Kendall, M.G., 1975. Rank auto-correlation methods. Charles Griffin, London.

Lenhart, T., Eckhardt, K., Fohrer, N. and Frede, H.-G., 2002. Comparison of two different approaches of sensitivity analysis. Physics and Chemistry of the Earth, Parts A/B/C, 27(9): 645-654.

Li, Y., Horton, R., Ren, T. and Chen, C., 2010. Prediction of annual reference evapotranspiration 
using climatic data. Agricultural Water Management, 97(2): 300-308.

Li, Y. and Sun, C., 2016. Impacts of the superimposed climate trends on droughts over 1961-2013 in Xinjiang, China. Theoretical and Applied Climatology, DOI: $10.1007 / \mathrm{s} 00704-016-1822-\mathrm{x}$

Li, Y., Yao, N., Sahin, S. and Appels, W.M., 2016. Spatiotemporal variability of four precipitation-based drought indices in Xinjiang, China. Theoretical and Applied Climatology, DOI: $10.1007 / \mathrm{s} 00704-016-1827-5$.

Li, Z., Chen, Y., Yang, J. and Wang, Y., 2014. Potential evapotranspiration and its attribution over the past 50 years in the arid region of Northwest China. Hydrological Processes, 28(3): $1025-1031$

Liu, X. M., Zheng, H. X., Zhang, M. H., Liu, C. M., 2011. Identification of dominant climate factor for pan evaporation trend in the Tibetan Plateau. Journal of Geographical Sciences, 21(4): 594-608.

Liu, Q. and Yang, Z., 2010. Quantitative estimation of the impact of climate change on actual evapotranspiration in the Yellow River Basin, China. Journal of Hydrology, 395(3): 226-234.

Mann, H.B., 1945. Nonparametric tests against trend. Econometrica: Journal of the Econometric Society, 13: 245-259.

McKenney, M.S. and Rosenberg, N.J., 1993. Sensitivity of some potential evapotranspiration estimation methods to climate change. Agricultural and Forest Meteorology, 64(1): 81-110.

McVicar, T.R., Roderick, M.L., Donohue, R.J., Li, L., Van Niel, T.G., Thomas, A., Grieser, J., Jhajharia, D., Himri, Y., Mahowald, N.M., V, M.A., Kruger, A.C., Rehman, S. and Dinpashohl, Y., 2012. Global review and synthesis of trends in observed terrestrial 
near-surface wind speeds: Implications for evaporation. Journal of Hydrology, 416: 182-205.

McVicar, T.R., Van Niel, T.G., Li, L., Hutchinson, M.F., Mu, X. and Liu, Z., 2007. Spatially distributing monthly reference evapotranspiration and pan evaporation considering topographic influences. Journal of Hydrology, 338(3): 196-220.

Partal, T. and Kahya, E., 2006. Trend analysis in Turkish precipitation data. Hydrological Processes, 20(9): 2011-2026.

Priestley, C. and Taylor, R., 1972. On the assessment of surface heat flux and evaporation using large-scale parameters. Monthly Weather Review, 100(2): 81-92.

Sen, P.K., 1968. Estimates of the regression coefficient based on Kendall's tau. Journal of the American Statistical Association, 63(324): 1379-1389.

Slatyer, R.O. and McIlroy, I.C., 1961. Practical Microclimatology. CSIRO, Melbourne, Australia.

Tabari, H. and Hosseinzadeh Talaee, P. 2014. Sensitivity of evapotranspiration to climatic change in different climates. Global and Planetary Change, 115: 16-23.

Tabari, H., Aeini, A., Hosseinzadeh Talaee, P. and Shifteh Some'e, B., 2012. Spatial distribution and temporal variation of reference evapotranspiration in arid and semi-arid regions of Iran. Hydrological Processes, 26: 500-512.

Tabari, H., Marofi, S., Aeini, A., Hosseinzadeh Talaee, P. and Mohammadi, K., 2011. Trend analysis of reference evapotranspiration in the western half of Iran. Agricultural and Forest Meteorology, 151(2): 128-136.

Tang, B., Tong, L., Kang, S. and Zhang, L., 2011. Impacts of climate variability on reference evapotranspiration over 58 years in the Haihe river basin of north China. Agricultural Water Management, 98(10): 1660-1670.

Thomas, A., 2000. Spatial and temporal characteristics of potential evapotranspiration trends over 
China. International Journal of Climatology, 20(4): 381-396.

Thornthwaite, C.W., 1948. An approach toward a rational classification of climate. Geographical Review, 38(1): 55-94.

Wu, Z. and Huang, N.E., 2009. Ensemble empirical mode decomposition: a noise-assisted data analysis method. Advances in Adaptive Data Analysis, 1(01): 1-41.

Xu, C., Gong, L., Jiang, T., Chen, D. and Singh, V., 2006. Analysis of spatial distribution and temporal trend of reference evapotranspiration and pan evaporation in Changjiang (Yangtze River) catchment. Journal of Hydrology, 327(1): 81-93.

Yin, Y., Wu, S., Chen, G. and Dai, E., 2010. Attribution analyses of potential evapotranspiration changes in China since the 1960s. Theoretical and Applied Climatology, 101(1-2): 19-28.

Yue, S. and Wang, C.Y., 2002. Regional streamflow trend detection with consideration of both temporal and spatial correlation. International Journal of Climatology, 22(8): 933-946. 
Table 1 The combinations of detrended or observed climatic variables (CVs) in the preset 15 scenarios. $\sqrt{ }$ - the $\mathrm{CV}$ was detrended in the scenario and used for recalculating $E T_{\mathrm{o}}$.

\begin{tabular}{|c|c|c|c|c|c|c|c|c|c|c|c|c|c|c|c|}
\hline \multirow{2}{*}{$\mathrm{CV}$} & \multicolumn{15}{|c|}{ Scenario } \\
\hline & 1 & 2 & 3 & 4 & 5 & 6 & 7 & 8 & 9 & 10 & 11 & 12 & 13 & 14 & 15 \\
\hline$T_{\min }\left({ }^{\circ} \mathrm{C}\right)$ & & $\sqrt{ }$ & & & $\sqrt{ }$ & $\sqrt{ }$ & & $\sqrt{ }$ & & & & & & & $\sqrt{ }$ \\
\hline$T_{\text {ave }}\left({ }^{\circ} \mathrm{C}\right)$ & & & $\sqrt{ }$ & & $\sqrt{ }$ & & $\sqrt{ }$ & $\sqrt{ }$ & & & & & & & $\sqrt{ }$ \\
\hline$T_{\max }\left({ }^{\circ} \mathrm{C}\right)$ & & & & $\sqrt{ }$ & & $\sqrt{ }$ & $\sqrt{ }$ & $\sqrt{ }$ & & & & & & & $\sqrt{ }$ \\
\hline$U_{2}(\mathrm{~m} / \mathrm{s})$ & & & & & & & & & $\sqrt{ }$ & & & & $\sqrt{ }$ & $\sqrt{ }$ & $\sqrt{ }$ \\
\hline$R H(\%)$ & & & & & & & & & & $\sqrt{ }$ & & $\sqrt{ }$ & $\sqrt{ }$ & & $\sqrt{ }$ \\
\hline$n(\mathrm{~h})$ & & & & & & & & & & & $\sqrt{ }$ & $\sqrt{ }$ & & $\sqrt{ }$ & $\sqrt{ }$ \\
\hline
\end{tabular}


Table 2 Results of trend test and abrupt changes of the CVs in Xinjiang. $Z_{\mathrm{m}}$-MMK test statistic, * -pass the $95 \%$ significance level, $b$-Sen's slope,$Y_{\mathrm{AC}}$-year with an abrupt change, $P_{\mathrm{sl}}$-significant level, NX-north Xinjiang, SX-south Xinjiang, EX-entire Xinjiang, $P$-precipitation.

\begin{tabular}{|c|c|c|c|c|c|c|c|c|c|}
\hline \multirow{2}{*}{$\begin{array}{l}\text { Sub-region } \\
\mathrm{CV}\end{array}$} & \multicolumn{3}{|c|}{ NX } & \multicolumn{3}{|c|}{ SX } & \multicolumn{3}{|c|}{ EX } \\
\hline & $Z_{\mathrm{m}}$ & $b$ & $Y_{\mathrm{AC}}$ & $Z_{\mathrm{m}}$ & $b$ & $Y_{\mathrm{AP}}$ & $Z_{\mathrm{m}}$ & $b$ & $Y_{\mathrm{AC}}$ \\
\hline$T_{\min }\left({ }^{\circ} \mathrm{C}\right)$ & $1.99 *$ & 0.056 & 1993 & 1.92 & 0.047 & 1992 & $2.03 *$ & 0.053 & 1993 \\
\hline$T_{\mathrm{ave}}\left({ }^{\circ} \mathrm{C}\right)$ & 1.89 & 0.038 & 1993 & 1.88 & 0.030 & 1996 & 1.91 & 0.036 & 1996 \\
\hline$T_{\max }\left({ }^{\circ} \mathrm{C}\right)$ & $3.12 *$ & 0.024 & 1996 & 1.63 & 0.022 & 1996 & 1.68 & 0.024 & 1997 \\
\hline$U_{2}(\mathrm{~m} / \mathrm{s})$ & -1.61 & -0.015 & 1980 & -1.31 & -0.014 & 1977 & -1.37 & -0.015 & 1978 \\
\hline$R H(\%)$ & 0.161 & 0.015 & 1974 & 0.667 & 0.031 & 1975 & 0.652 & 0.024 & - \\
\hline$n(\mathrm{~h})$ & -1.50 & -0.009 & 1978 & $-2.45^{*}$ & -0.007 & - & -1.28 & -0.007 & 1971 \\
\hline$P(\mathrm{~mm})$ & 1.62 & 0.106 & 1987 & $2.42 *$ & 0.040 & 1986 & 1.69 & 0.072 & 1987 \\
\hline$E T_{\mathrm{o}}(\mathrm{mm})$ & -1.76 & -0.970 & 1979 & -1.16 & -1.77 & 1975 & -1.11 & -1.28 & 1975 \\
\hline
\end{tabular}


Table 3 Pearson correlation coefficients $(r)$ between $E T_{\mathrm{o}}$ and the involved CVs at different significant levels $\left(P_{\mathrm{sl}}\right)$ in $\mathrm{S}-1$.

\begin{tabular}{ccccccc}
\hline Region & $\mathrm{NX}$ & $\mathrm{NX}$ & $\mathrm{SX}$ & $\mathrm{SX}$ & $\mathrm{EX}$ & $\mathrm{EX}$ \\
$\mathrm{CV}$ & $r$ & $P_{\mathrm{sl}}$ & $r$ & $P_{\mathrm{sl}}$ & $r$ & $P_{\mathrm{sl}}$ \\
\hline$T_{\min }\left({ }^{\circ} \mathrm{C}\right)$ & 0.027 & 0.846 & -0.291 & 0.034 & -0.159 & 0.254 \\
$T_{\text {ave }}\left({ }^{\circ} \mathrm{C}\right)$ & 0.243 & 0.080 & -0.133 & 0.341 & -0.105 & 0.452 \\
$T_{\max }\left({ }^{\circ} \mathrm{C}\right)$ & 0.438 & 0.001 & 0.056 & 0.689 & 0.227 & 0.103 \\
$U_{2}(\mathrm{~m} / \mathrm{s})$ & 0.395 & 0.003 & 0.751 & $<0.001$ & 0.596 & $<0.001$ \\
$R H(\%)$ & -0.856 & $<0.001$ & -0.666 & $<0.001$ & -0.764 & $<0.001$ \\
$n(\mathrm{~h})$ & 0.742 & $<0.001$ & 0.691 & $<0.001$ & 0.810 & $<0.001$ \\
\hline
\end{tabular}


Table 4 The statistical properties of LS and $b$ for the studied CVs. SD-standard error, RMSE-root mean square error.

\begin{tabular}{cccccccc}
\hline $\mathrm{CV}$ & Range $_{\mathrm{LS}}$ & Range $_{b}$ & Average $_{\mathrm{LS}}$ & Average $_{b}$ & $\mathrm{SD}_{\mathrm{LS}}$ & $\mathrm{SD}_{b}$ & $\mathrm{RMSE}$ \\
\hline$T_{\min }\left({ }^{\circ} \mathrm{C}\right)$ & {$[-0.026,0.116]$} & {$[-0.025,0.133]$} & 0.049 & 0.048 & 0.025 & 0.026 & 0.004 \\
$T_{\text {ave }}\left({ }^{\circ} \mathrm{C}\right)$ & {$[-0.009,0.084]$} & {$[-0.009,0.085]$} & 0.032 & 0.032 & 0.017 & 0.017 & 0.001 \\
$T_{\max }\left({ }^{\circ} \mathrm{C}\right)$ & {$[-0.001,0.071]$} & {$[-0.001,0.070]$} & 0.023 & 0.022 & 0.011 & 0.011 & 0.001 \\
$U_{2}(\mathrm{~m} / \mathrm{s})$ & {$[-0.061,0.071]$} & {$[-0.060,0.070]$} & -0.015 & -0.014 & 0.017 & 0.019 & 0.004 \\
$R H(\%)$ & {$[-0.161,0.238]$} & {$[-0.160,0.238]$} & 0.005 & 0.002 & 0.079 & 0.081 & 0.010 \\
$n(\mathrm{~h})$ & {$[-11.1,9.14]$} & {$[-12.1,9.65]$} & -1.74 & -1.67 & 4.25 & 4.28 & 0.596 \\
\hline
\end{tabular}


Figure Captions

Figure 1 Geological information of the study sites in Xinjiang, China. The color legend represents the elevation ( $\mathrm{m}$ above sea level).

Figure 2 The observed CVs and their linear and nonlinear trends in NX, SX and EX.

Figure 3 Temporal variations of annual $E T_{\mathrm{o}}$ and their trends in NX, SX and EX over 1961-2013.

Figure 4 Curves of $u(\mathrm{t})$ and $u^{\prime}(\mathrm{t})$ for the involved CVs and $E T_{\mathrm{o}}$ in NX, SX and EX over 1961-2014.

Figure 5 Variations of annual $E T_{\mathrm{o}}$ estimated with linearly detrended CVs (Group I) in NX, SX and EX over 1961-2013.

Figure 6 Variations of annual $E T_{\mathrm{o}}$ estimated with nonlinearly detrended CVs (Group II) in NX, SX and EX over 1961-2013.

Figure 7 Variations of annual $D_{\mathrm{ETo}}$ for scenarios 2 to 15 of Groups I and II in NX, SX and EX over 1961-2013.

Figure 8 Statistical properties of $D_{\mathrm{ETo}}$ for S-2 to S-15 in Groups I and II in NX, SX and EX over 1961-2013.

Figure 9 Variations of annual $E T_{\mathrm{o}}$ for S-1, S-15 in Group I and S-15 in Group II over 1961-2013 for NX, SX and EX.

Figure 10 Decadal averages and periodical linear trends of $E T_{\mathrm{o}}$ in $\mathrm{EX} . \mathrm{Y}_{\mathrm{AC}, 1}, \mathrm{Y}_{\mathrm{AC}, 2}, \mathrm{Y}_{\mathrm{AC}, 3}$ and $\mathrm{Y}_{\mathrm{AC}, 4}$ represent the 1st, 2nd, third, and the forth abrupt change years.

Figure 11 Variations of annual $I_{\mathrm{A}}$ using $E T_{\mathrm{o}}$ in S-1 and S-15 in Groups I and II for NX, SX and EX over 1961-2013.

Figure 12 Comparison between linear slope (LS) and Sen's slope (b) for the related CVs at each site and sub-region of Xinjiang, China. Site numbers 54, 55 and 56 referred to NX, SX, and EX, respectively. 


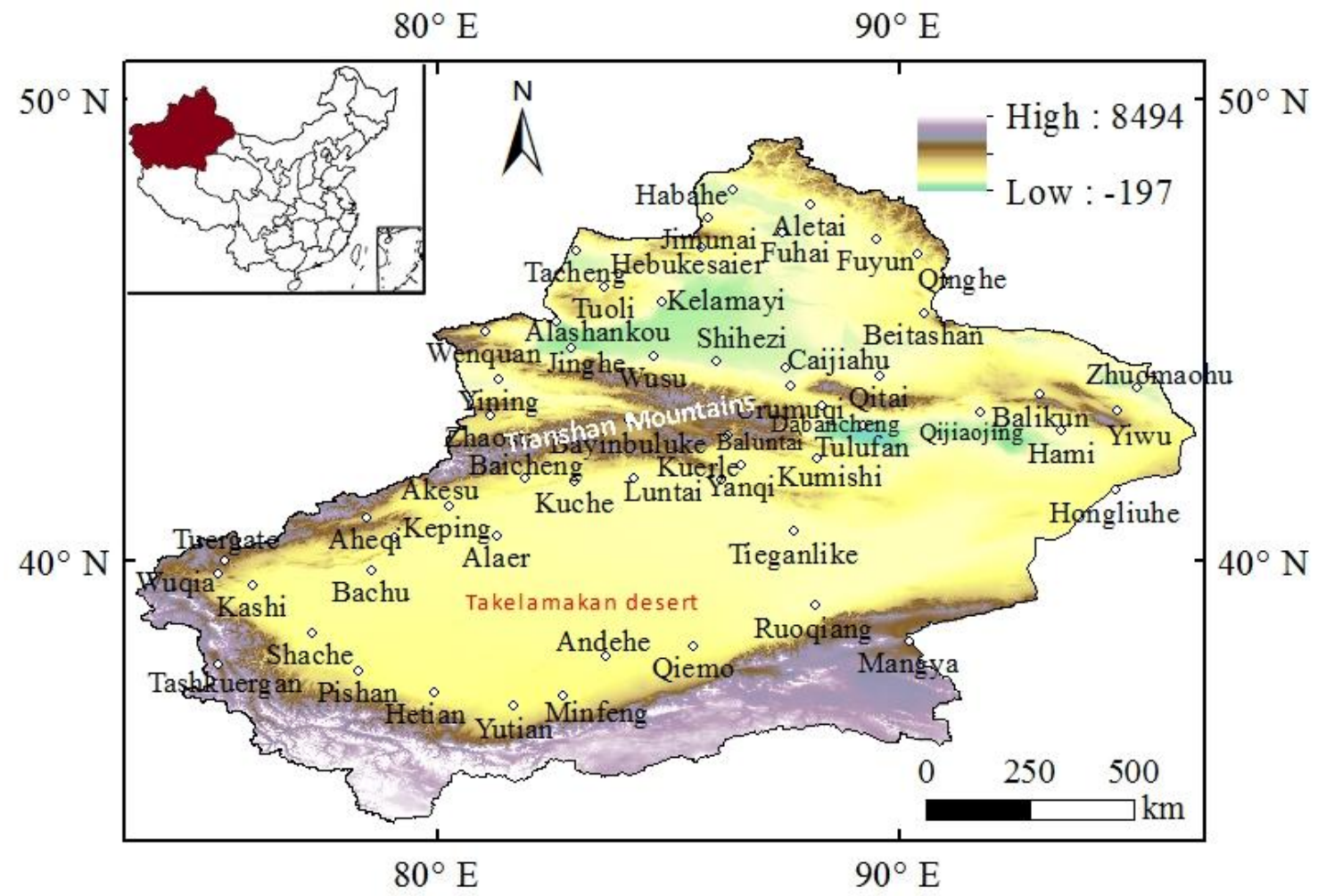

Figure 1 Geological information of the study sites in Xinjiang, China. The color legend represents the elevation ( $\mathrm{m}$ above sea level). 

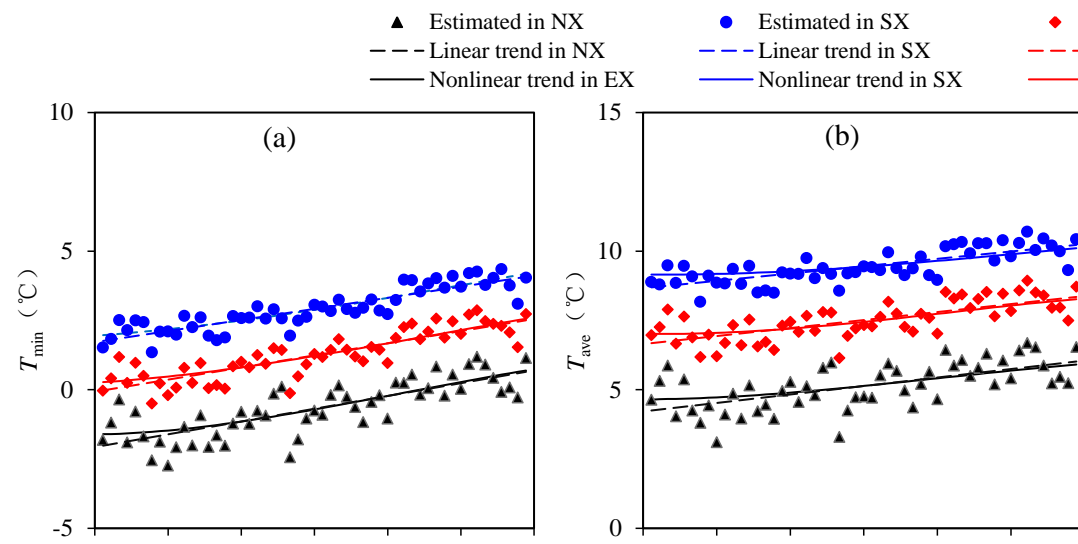

Estimated in EX

- Linear trend in EX

- Estimated in NX

- - Linear trend in SX

Nonlinear trend in EX
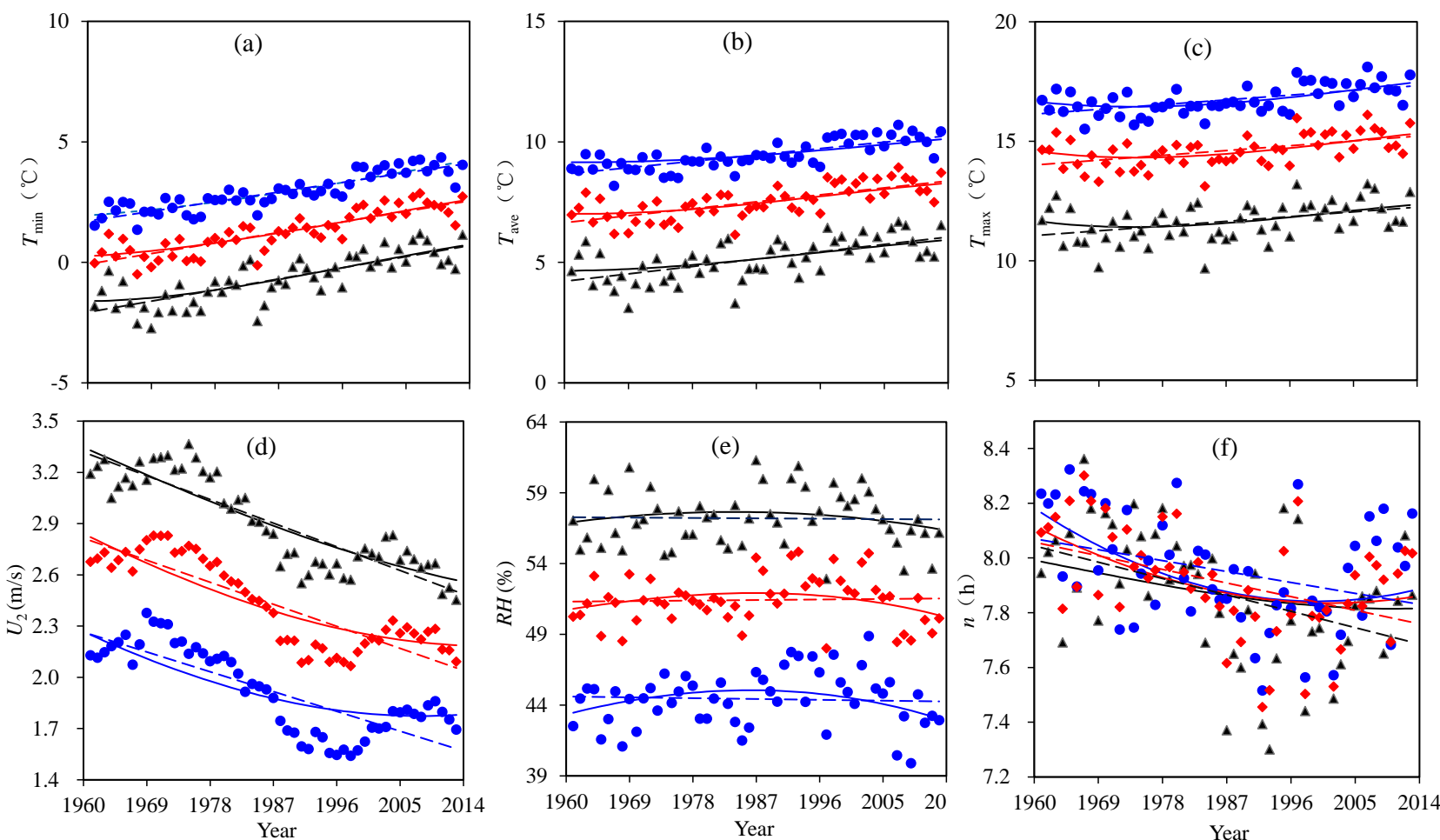

Figure 2 The observed CVs and their linear and nonlinear trends in NX, SX and EX. 
$\Delta$ Estimated in NX $\quad$ Estimated in SX $\bullet \quad$ Estimated in EX

$---\cdot$ Linear trend in NX $\quad---\cdot$ Linear trend in SX $\quad---\cdot$ Linear trend in EX

- Nonlinear trend in EX - Nonlinear trend in SX - Nonlinear trend in EX

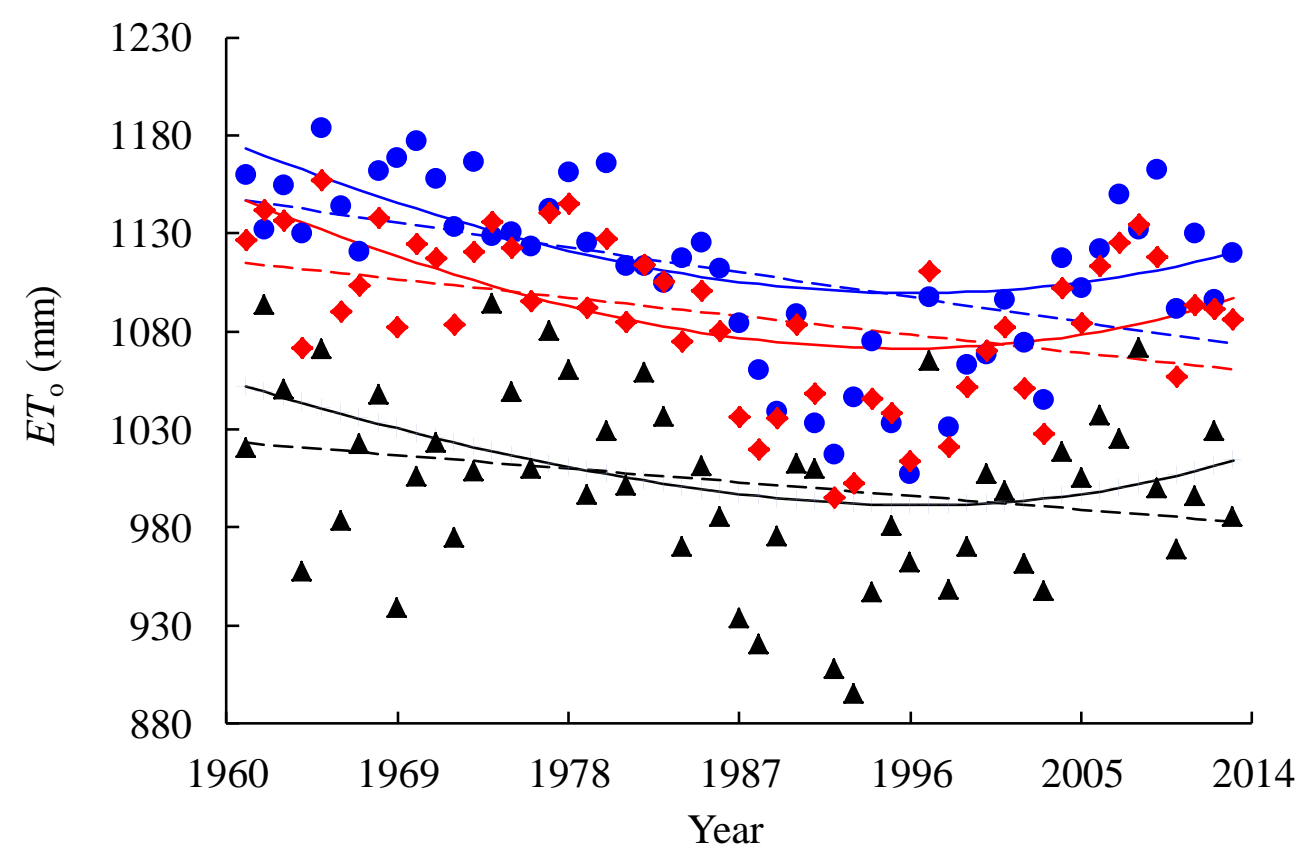

Figure 3 Temporal variations of annual $E T_{\mathrm{o}}$ and their trends in NX, SX and EX over 1961-2013. 


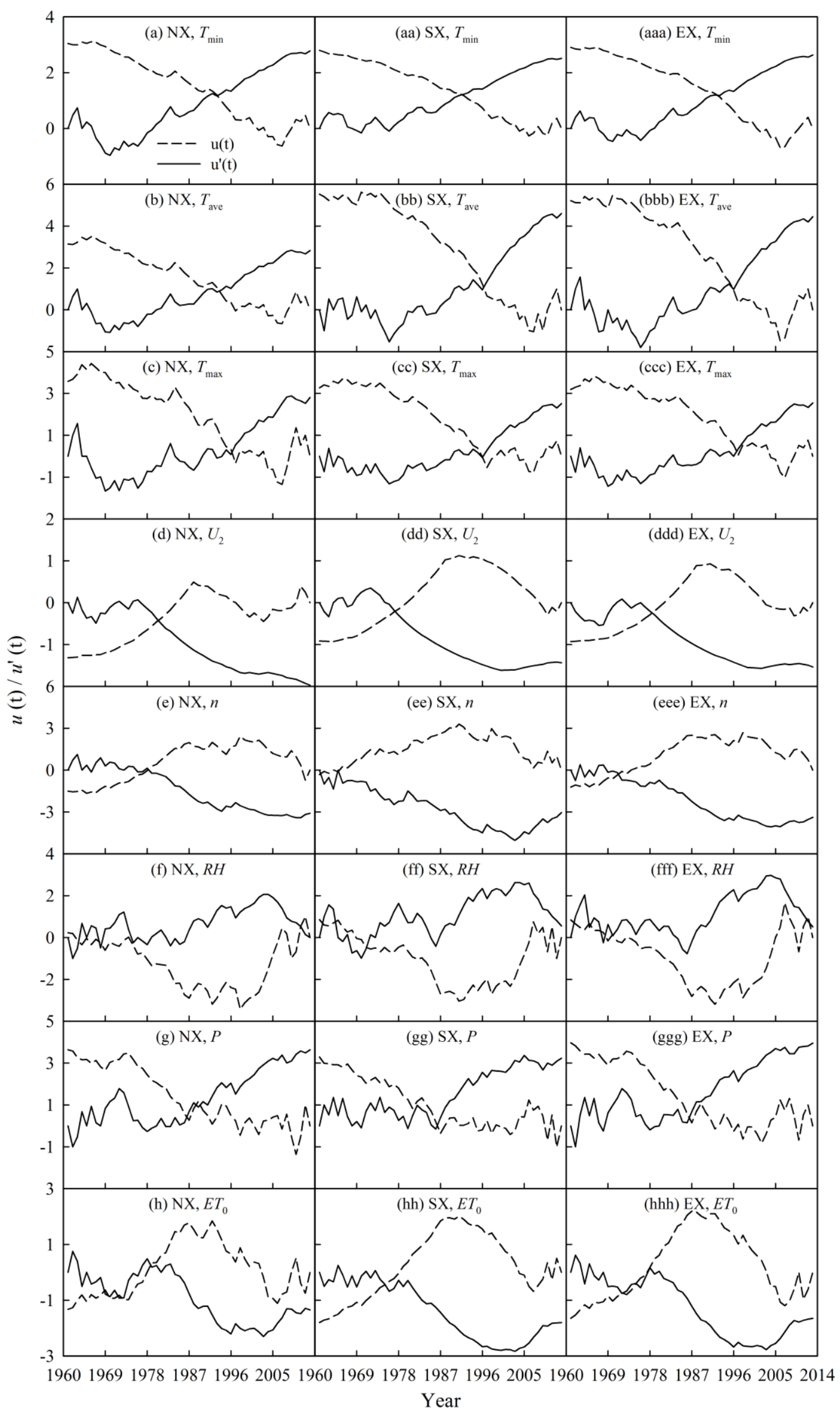

Figure 4 Curves of $u(\mathrm{t})$ and $u^{\prime}(\mathrm{t})$ for the involved CVs and $E T_{\mathrm{o}}$ in NX, SX and EX over 1961-2014. 


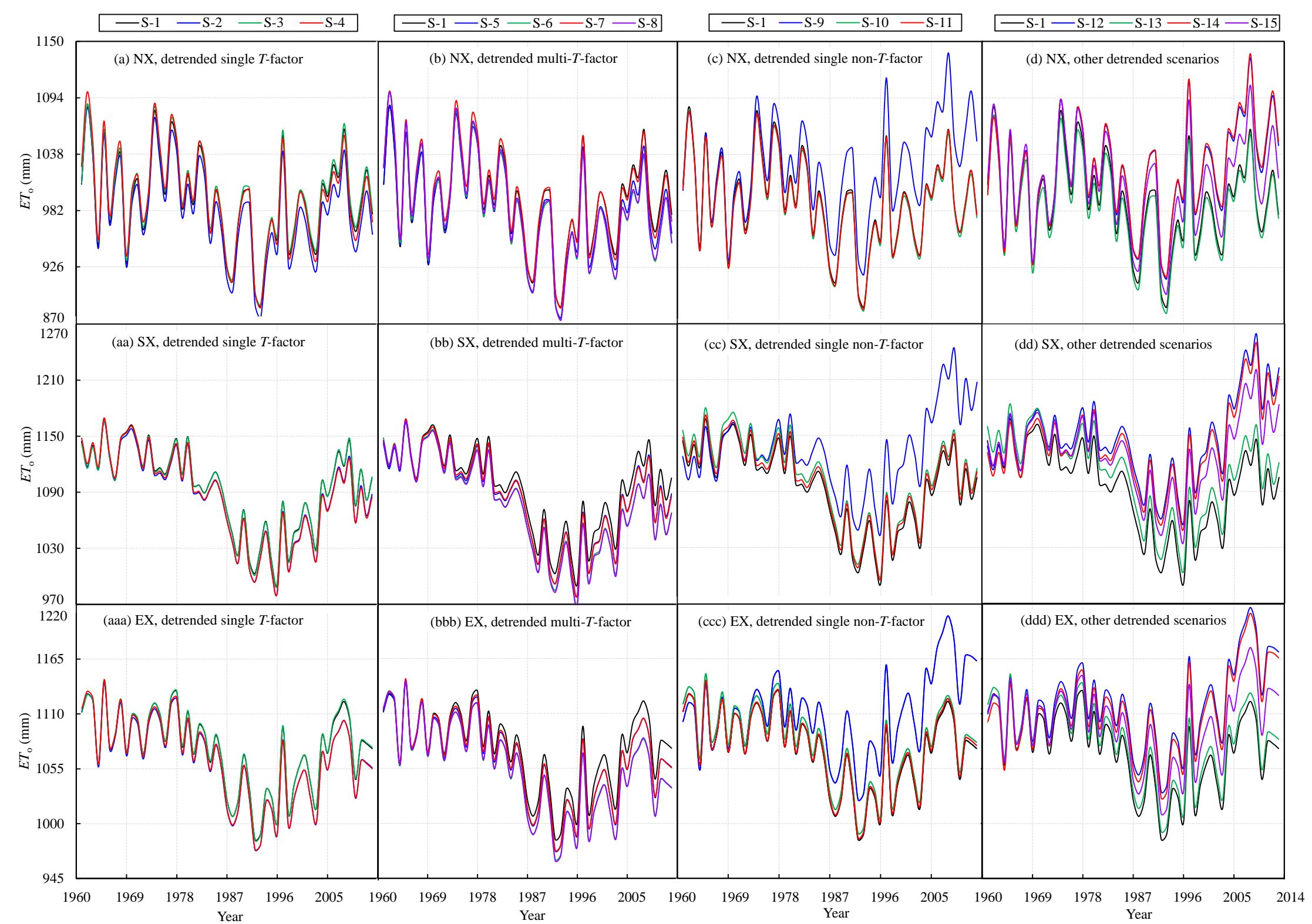

Figure 5 Variations of annual $E T_{\mathrm{o}}$ estimated with linearly detrended CVs (Group I) in NX, SX and EX over 1961-2013. 


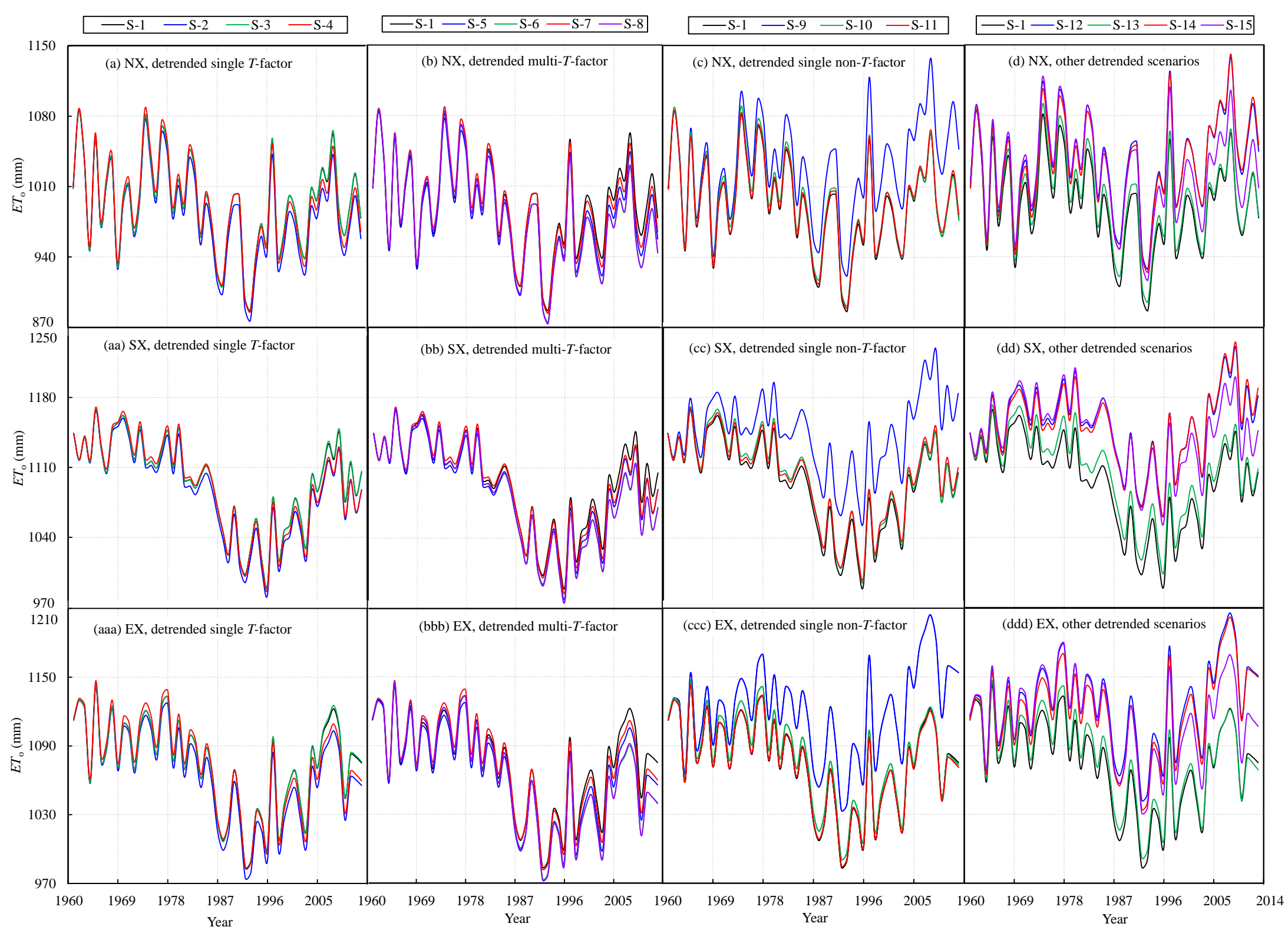

Figure 6 Variations of annual $E T_{\mathrm{o}}$ estimated with nonlinearly detrended CVs (Group II) in NX, SX and EX over 1961-2013. 

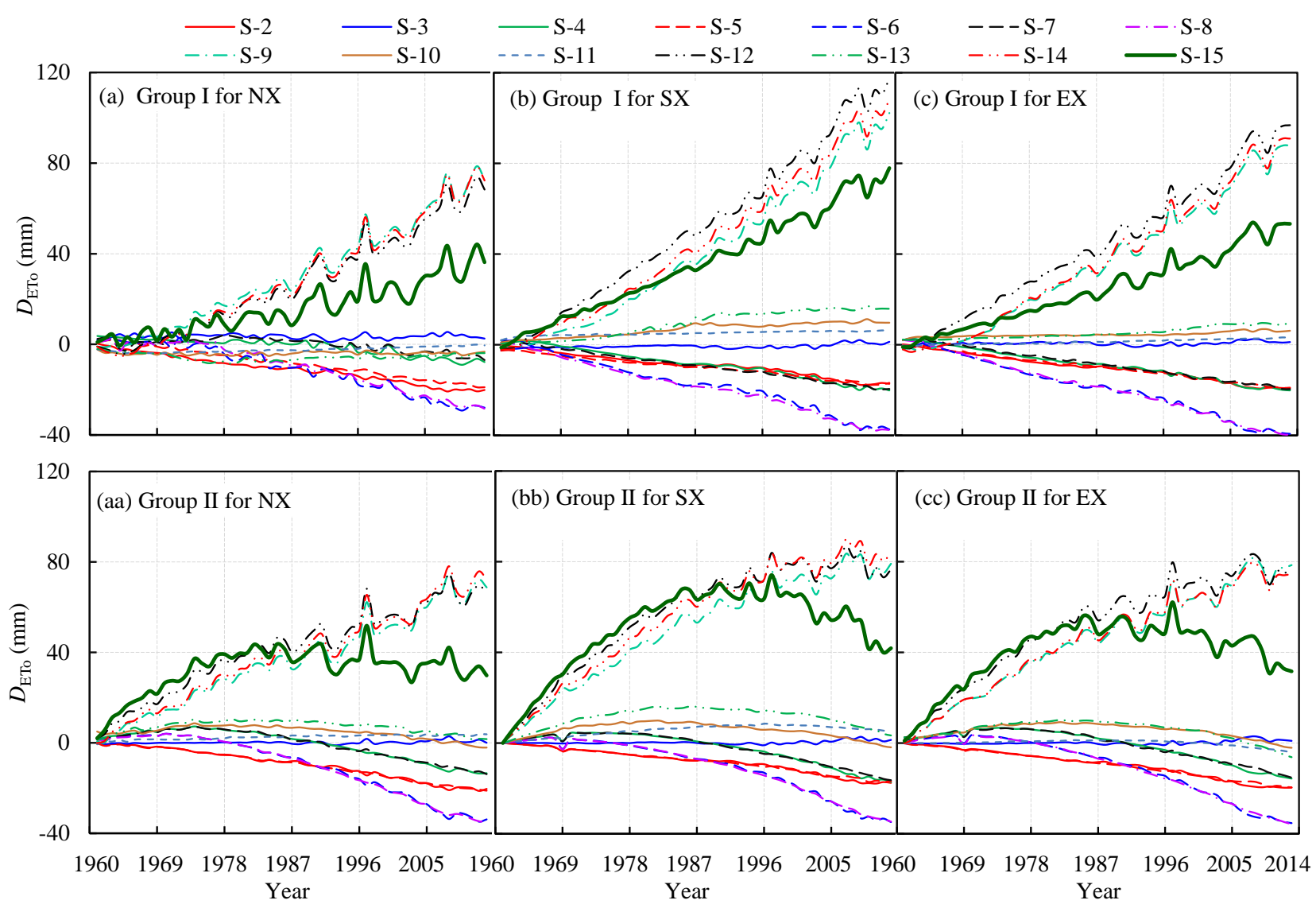

Figure 7 Variations of annual $D_{\mathrm{ETo}}$ for scenarios 2 to 15 of Groups I and II in NX, SX and EX over 1961-2013. 


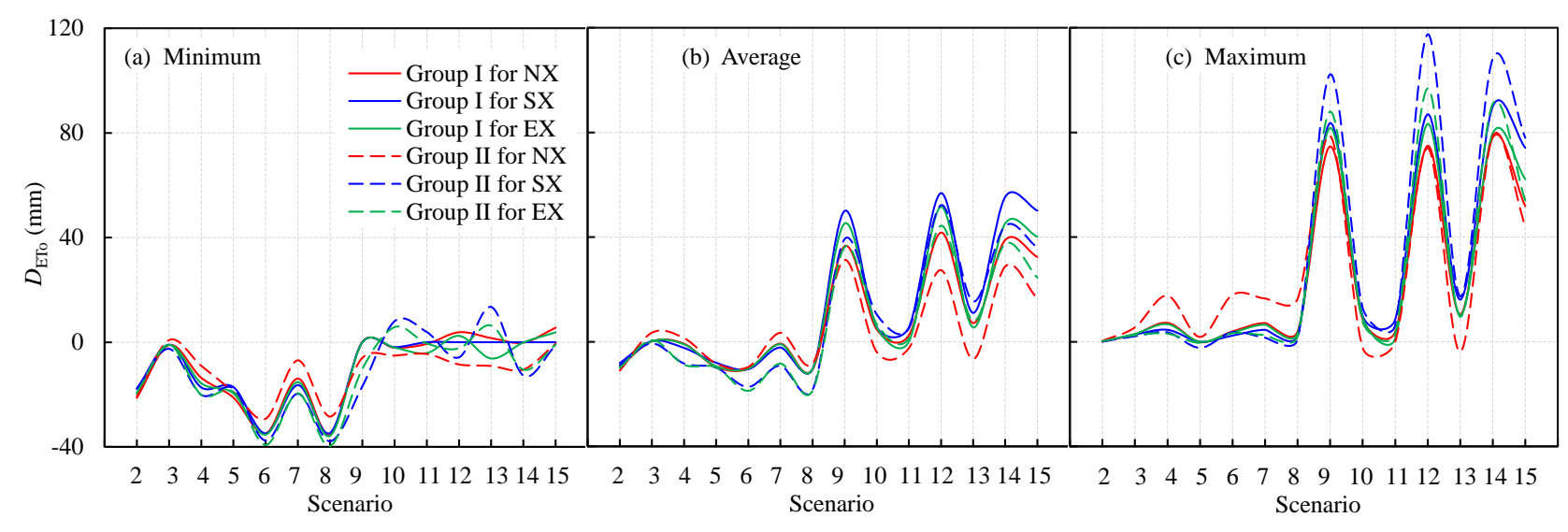

Figure 8 Statistical properties of $D_{\mathrm{ETo}}$ for S-2 to S-15 in Groups I and II in NX, SX and EX over

1961-2013. 


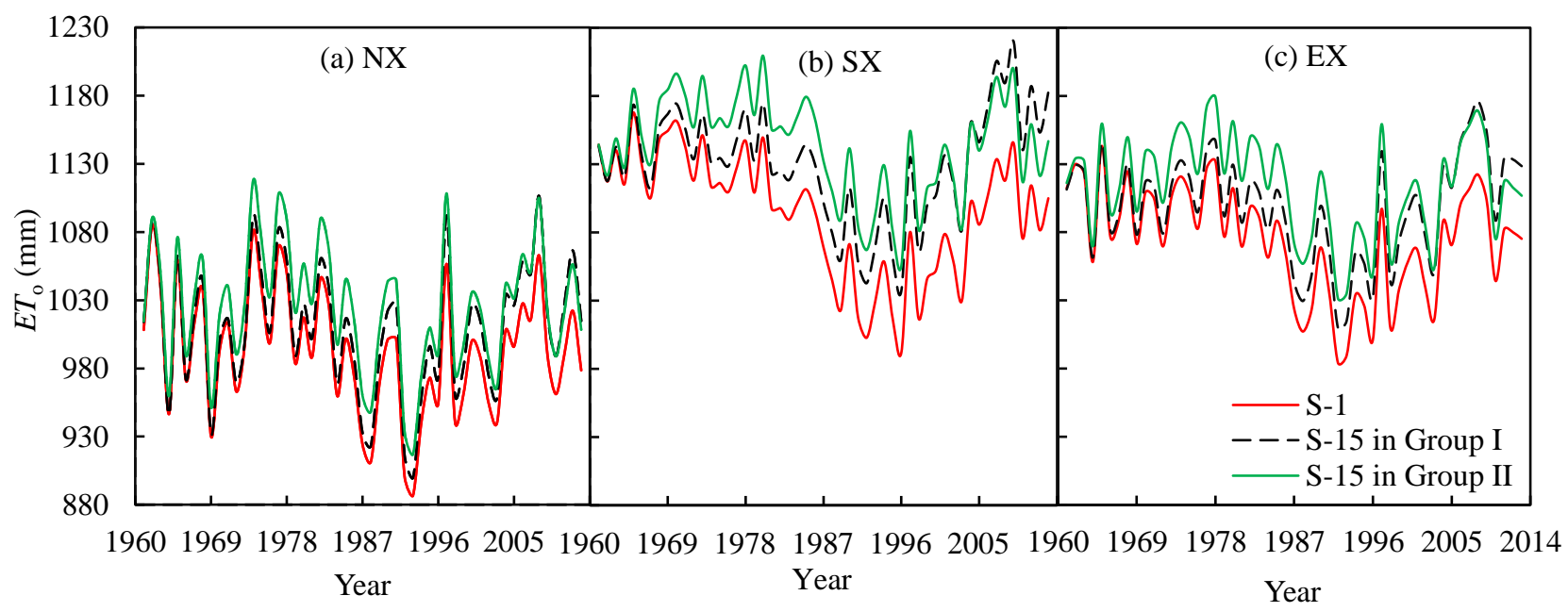

Figure 9 Variations of annual $E T_{\mathrm{o}}$ for S-1, S-15 in Group I and S-15 in Group II over 1961-2013 for NX, SX and EX. 


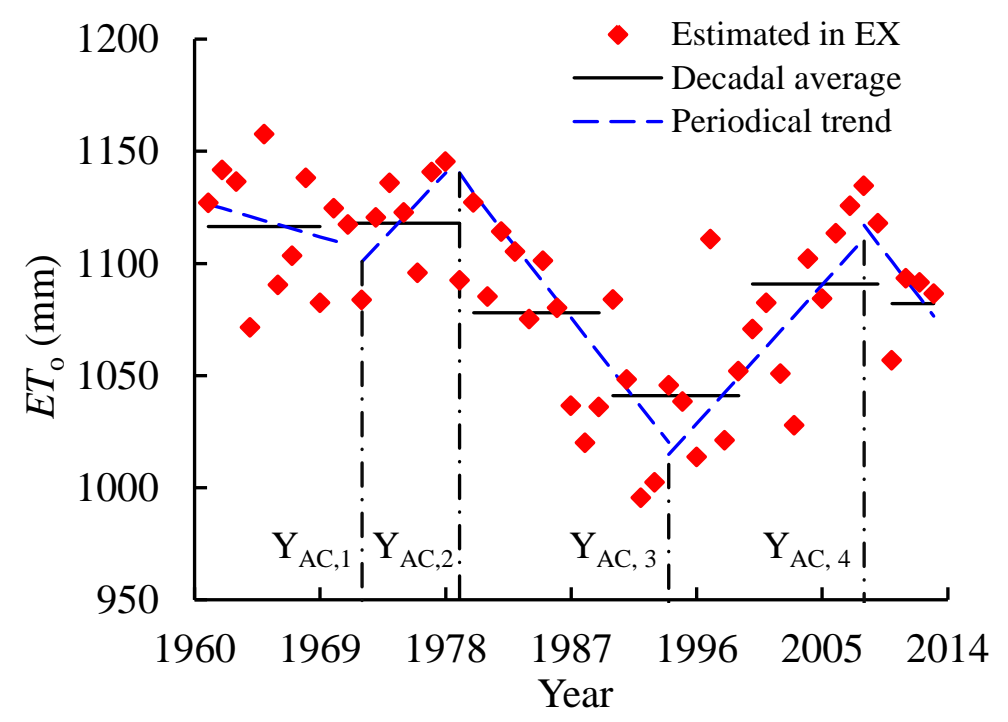

Figure 10 Decadal average and periodical linear trends of $E T_{\mathrm{o}}$ in $\mathrm{EX}$. $\mathrm{Y}_{\mathrm{AC}, 1}, \mathrm{Y}_{\mathrm{AC}, 2}, \mathrm{Y}_{\mathrm{AC}, 3}$ and $\mathrm{Y}_{\mathrm{AC}, 4}$ represent the 1st, 2nd, third, and the forth abrupt change years. 


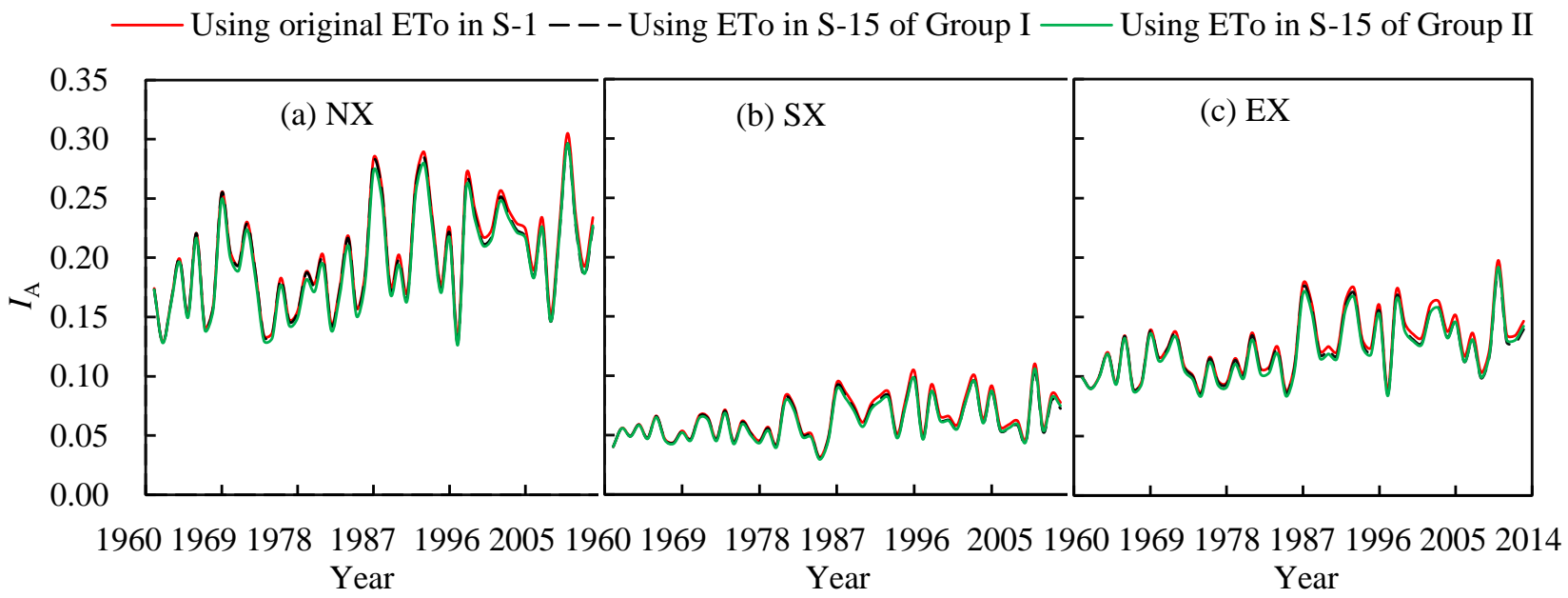

Figure 11 Variations of annual $I_{\mathrm{A}}$ using $E T_{\mathrm{o}}$ in S-1 and S-15 in Groups I and II for NX, SX and EX over 1961-2013. 


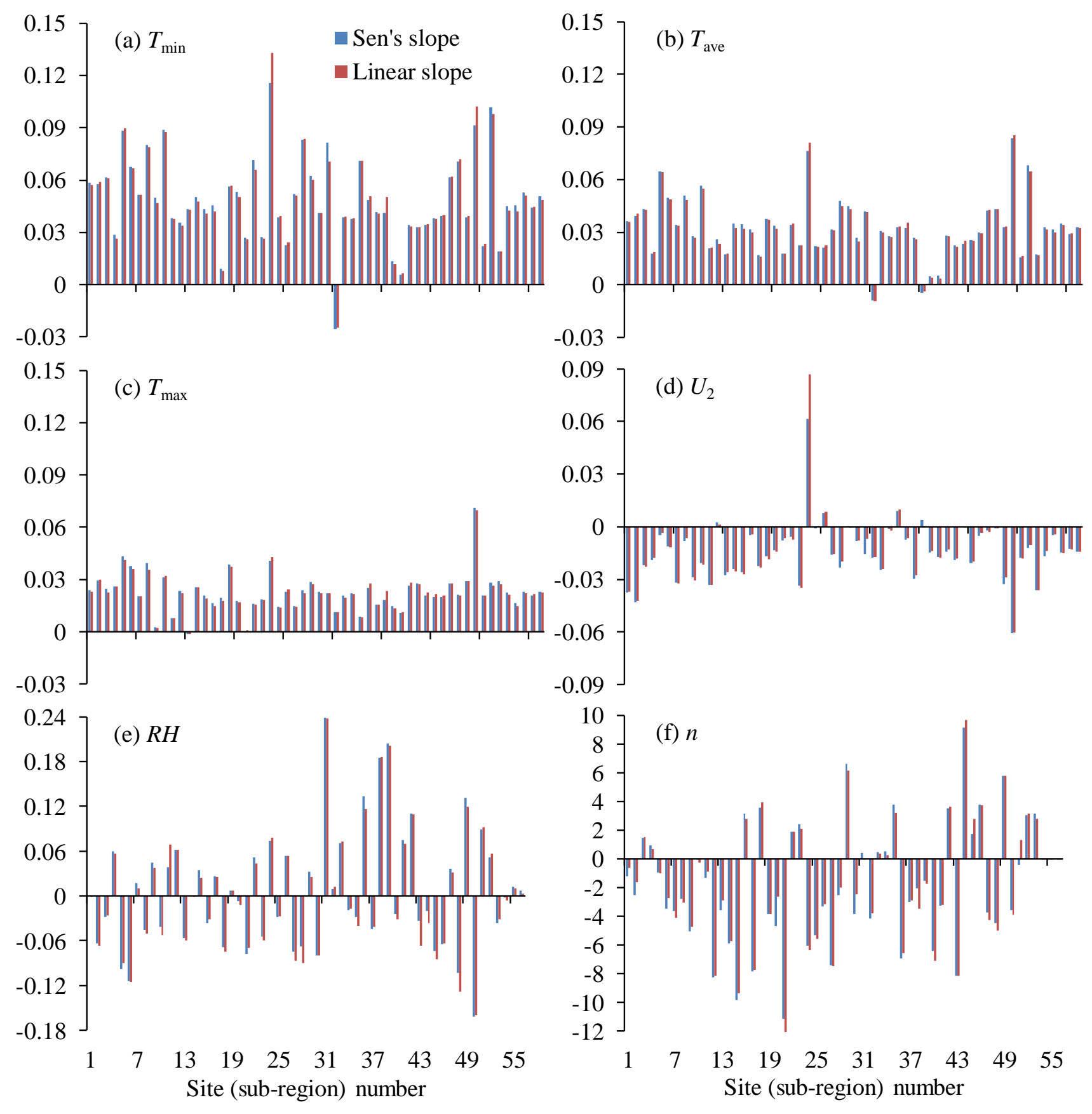

Figure 12 Comparison between linear slope (LS) and Sen's slope (b) for the related CVs at each site and sub-region of Xinjiang, China. Site numbers 54, 55 and 56 referred to NX, SX, and EX, respectively. 
Graphical abstract

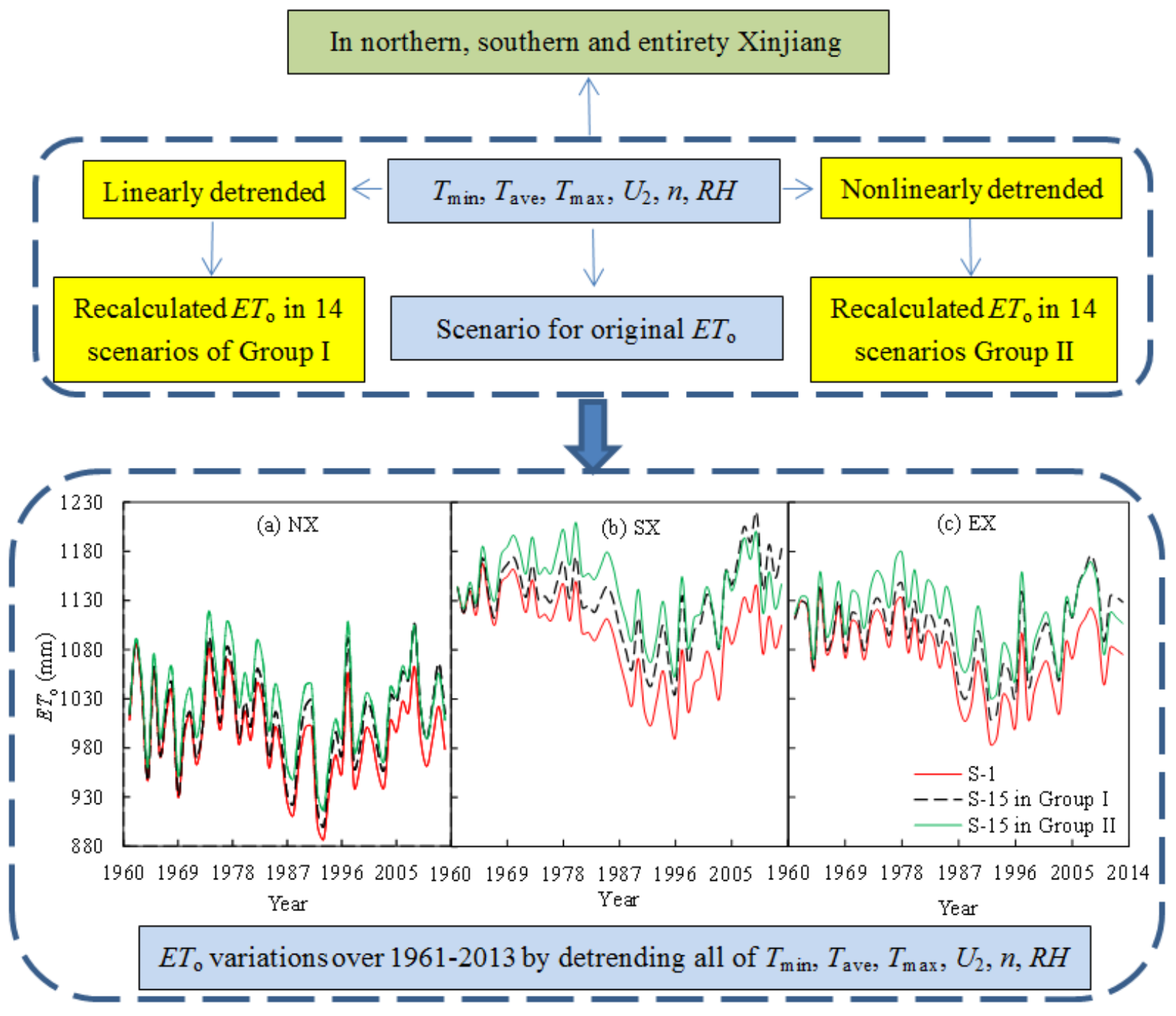

